\title{
Data Truncation Bias, Loss Firms, and Accounting Anomalies
}

\author{
Siew Hong Teoh \\ Paul Merage School of Business, University of California, Irvine \\ steoh@uci.edu \\ Yinglei Zhang \\ School of Accountancy, Chinese University of Hong Kong \\ yinglei_acy@baf.msmail.cuhk.edu.hk
}

This Revision: July 2009

First Draft: August 2005

We thank workshop participants at University of California, Irvine, Chinese University of Hong Kong, the 2006 Financial Accounting Research Section Meeting 2006, 2006 American Accounting Association Meetings. We also thank Anne Beatty, David Hirshleifer, Joanna Ho, Bin Ke, Mort Pincus, Scott Richardson (FARS discussant), Doug Schroeder, Charles Wasley (AAA discussant), T J Wong, and Huai Zhang for valuable comments. 


\section{Data truncation bias, loss firms,}

\section{and accounting anomalies}

After performing a Least Trimmed Square procedure at 1\%, Kraft, Leone, and Wasley (2006) find an inverted-U relation between Accruals or net operating assets (NOA) and subsequent one-year abnormal returns. They argue that this opposes behavioral explanations for the Accrual and NOA anomalies. We show that the inverted-U relation is a spurious consequence of the truncation bias noted in Kothari, Sabino, and Zach (2005). LTS trimming for these anomalies effectively trims observations by the value of the dependent variable (returns). We show that because returns skewness varies systematically with the accounting predictor, the LTS trimming induces a truncation bias that varies systematically across the accounting predictors. The variation in returns skewness is related to the variation in the incidence of loss firms across the accounting predictors. Among profit firms, which have less skewed returns and so are less subject to the truncation bias, the negative monotonic relation between accounting predictors and subsequent abnormal returns is robust to trimming. Thus, ex post non-random trimming of returns can spuriously induce evidence against either the efficient market hypothesis or behavioral theories. Additionally, this paper shows that the anomalies survive trimming, despite the truncation bias, when a larger set of asset pricing controls and test methods that control for cross-sectional dependence are used. 


\section{Introduction}

Sloan (1996) and Hirshleifer, Hou, Teoh, and Zhang (2004) find that asset-scaled operating accruals (Accruals) and net operating assets (NOA) are negative predictors of abnormal future stock returns. ${ }^{1}$ These authors suggest that the findings are consistent with investor failure to incorporate fully the information contained in financial reports owing to functional fixation on earnings or limited attention, and therefore consistent with imperfect rationality and inconsistent with the efficient markets hypothesis.

Kraft, Leone, and Wasley (2006, KLW hereafter) challenge the behavioral explanation for accounting anomalies based upon the effects of removing ex post extreme observations. They find that after conducting a Least Trimmed Squared (hereafter LTS) regression at 1\%, there is an inverted-U relation between Accruals or NOA and subsequent one-year buy and hold abnormal returns (BHAR). They argue that the behavioral theory predicts a monotonic relation between future returns and Accruals or NOA, and that this relation will not be driven by just a small fraction of the observations. They conclude that these results raise a severe challenge for behavioral theories of these anomalies. Relatedly, Kraft, Leone and Wasley (2005) report that the asset-scaled operating cash flows (CFO) anomaly is even stronger when observations with extreme returns are trimmed.

KLW's presumption that the effects on returns of psychological bias should be robust to trimming of a small fraction of the observations sounds plausible. A similar, superficially plausible claim is that rational asset pricing effects should be robust to the trimming of a small fraction of observations. However, Core (2006, p. 350) cautions that "in general, deleting data

\footnotetext{
1 A branch of the literature on the accrual anomaly focuses on earning management to take advantage of investor naiveté and influence the behavior of auditors, analysts, and investors (e.g., Teoh, Welch, and Wong (1998a, b), Ali, Hwang and Trombley (2000), Bradshaw, Richardson, and Sloan (2000), Xie (2001), Teoh and Wong (2002), Fairfield, Whisenant and Yohn (2003), Dechow and Ge (2006), Dechow, Richardson and Sloan (2007), Ali, Chen, Yao and Tong (2008), Levi (2008), and Louis, Robinson and Sbaraglia (2008)).
} 
based on the robust regression techniques employed and advocated by KLW seems inappropriate ... deleting extreme observations from skewed return data leads to biased estimates and can bias inferences.”

In this paper we explore the appropriateness of data deletion as a robustness test for the Accrual, NOA, and CFO anomalies. Because returns are right-skewed, Core (2006) noted that the LTS deletion effectively removes observations with large, positive abnormal returns in KLW. The procedure of choosing the composition of a sample based upon the value of the dependent variable creates post-selection bias. To draw inferences from a post-selected sample as if this bias were not present would be questionable.

Kothari, Sabino and Zach (2005) stress that non-random data deletion spuriously induces return predictability when the distribution of security returns is right-skewed. Trimming of extreme observations can therefore cause spurious rejection of the efficient markets hypothesis. They also emphasize that in setting prices an efficient market rationally incorporates the possibility of firms earning extreme returns in the future. Truncation of extreme observations which are not data errors from a right-skewed return distribution biases downward the estimated mean return. We refer to this as truncation bias; it is a special case of the familiar statistical concept of selection bias.

We show here that the LTS procedure generates a severe truncation bias that explains the findings of inverted U-shape finding. We provide evidence that the LTS procedure trims extreme returns in a way that systematically varies with the return-predicting accounting variables. We find that truncation bias varies in an inverted U-shape pattern with the accounting predictors. In some test specifications (such as those used by KLW) this truncation-bias-induced pattern is strong enough to dominate the underlying monotonic pattern of the anomaly, trimming results in 
an inverted U-shape relation. Thus, the finding of an inverted U-shape is spurious, and therefore uninformative about the robustness of these accounting anomalies.

Building upon the insight of Core (2006), we explore the source of the non-random deletion of observations in the LTS procedure as applied to accounting anomalies. We find the magnitude of the deletion-induced truncation bias varies with the accounting predictor, because truncation bias increases with the degree of right skewness of returns. Since loss firms tend to have greater right skewness in returns, we therefore explore whether the incidence of losses varies systematically with the accounting predictors.

Intuitively, since losing money is not viable in the long-term, loss firms are likely to engage in strategic business shifts (possibly associated with financial distress, high leverage, and restructuring). In consequence, we expect the future earnings and returns of loss firms to be much more variable than those of profit firms. Since downside stock returns are bounded below by $-100 \%$ but not bounded above, we expect higher dispersion in profitability to induce greater positive skewness. ${ }^{2}$

We show first that the truncation bias induced by trimming is related to the loss effect identified in Beneish et al. (2001). A loss indicator variable is introduced to the regression of returns on the accounting predictors. We find that it becomes a negative predictor for future returns in the trimmed sample (at 1\%) but has no predictive power in the untrimmed sample. Hence, the loss effect is induced spuriously by the truncation bias giving the illusion of return predictability, consistent with the argument of Kothari et al. (2005).

\footnotetext{
${ }^{2}$ Indeed, we find that the bottom percentile returns do not vary as much between profit and loss firms (-33\% versus $-52 \%$ respectively) as the top $99^{\text {th }}$ percentile returns ( $48 \%$ versus $100 \%$ respectively). Furthermore, loss firms are less likely than profit firms to be viable as going concerns in the long run. This creates a substantial probability of low profits should the firm fail, and a long right tail of more favorable outcomes should the firm survive. Such a situation can also create a lottery-like, positively skewed distribution of returns. For example, we document that among loss firms, monthly abnormal returns exceeding $+100 \%$ tend to cluster in high-tech industries, and increased dramatically after 1990. It is plausible that many hi-tech firms, especially during the 1990s high-tech boom, have had lottery-like return distributions (Barberis and Huang 2004).
} 
It follows that truncation will tend to bias estimated mean returns downward more for portfolios which are dominated by loss firms than portfolios which are dominated by profit firms. Therefore, if the frequency of losses varies systematically across Accruals/NOA/CFO deciles, the truncation bias from ex post trimming of extreme returns is related to the spurious loss effect. We document that the frequency of losses indeed decreases dramatically and monotonically with Accruals, NOA and CFO ranks among the lowest five deciles, but remains relatively constant among the highest five deciles.

It could still be argued that these accounting anomalies lack robustness if deleting a mere $1 \%$ of the sample can overturn the monotonic relations between returns and the return predictors. However, trimming even a small fraction of a sample can lead to large spurious effects because in general return-predicting variables explain only a small fraction of the variation in returns (low R-square). ${ }^{3}$ There is therefore strong ex ante reason to expect that deleting even a small fraction of observations based on their having extreme returns can easily have effects that are quite large relative to the relation being estimated. In other words, depending on the degree of positive skewness of returns, the magnitude of deletion-induced truncation bias for some deciles of the accounting predictor variable can indeed swamp the mean return for that decile with undeleted observations.

Although we regard the concern that anomalies are driven by only $1 \%$ of the population as conceptually unwarranted, we provide further evidence that in a major class of firms these anomalies are robust with respect to trimming. Since the right skewness of profit firms is weaker than that of loss firms, we investigate the effects of trimming on a sample with loss firms

\footnotetext{
3 This has to be the case if markets have even a minimal degree of efficiency. If a variable could predict future returns with a high R-square, it would provide an enormous low-risk money machine. Arbitrageurs have strong incentives to exploit such opportunities until predictive power is reduced to the point where arbitrage opportunities become riskier, Mashruwala, Rajgopal, and Shevlin (2006).
} 
removed. ${ }^{4}$ We find that even after trimming extreme returns, abnormal returns still decrease almost monotonically across the Accrual deciles, and monotonically across NOA deciles. Therefore, among profit firms these anomalies are so strong that they survive ex post trimming. Since profit firms make up a significant majority (79\%) of our sample, the evidence should reassure researchers that the anomalies are indeed robust.

On a distinct but equally important statistical issue, appropriate asset pricing methods and controls should be used to test for anomalies (Zach 2002). KLW controls only for size and their pooled OLS regressions use annual horizon abnormal returns. We examine the robustness of the anomalies to the inclusion of other standard asset pricing controls from the finance literature, including book-to-market, twelve-month momentum, and past one-month and three year returns (the short-term and long-term reversal effects). We use the Fama-Macbeth procedure to obtain appropriate test statistics as suggested by Peterson (2009), instead of relying on the $t$-statistics from a pooled OLS regression. The Fama-Macbeth method corrects for cross-sectional correlation of residuals. Finally, we use monthly returns instead of annual returns. This has two advantages. Monthly returns are less right-skewed than long horizon abnormal returns. Any extreme return will have less of an impact on the results because the estimated coefficients are averaged across the monthly regressions.

With the additional controls and improvement in test methods, we find that the truncation bias is smaller and that the inverted-U relation is much shallower for the Accruals anomaly in the trimmed full sample of firms. In the profit sample, trimming does not change the near monotonicity of the Accruals anomaly. The NOA anomaly is even more robust as the near monotonicity of returns to NOA is preserved with trimming either in the profit sample or in the

\footnotetext{
${ }^{4}$ Partitioning on ex ante firm characteristics such as loss or profit is statistically legitimate, and of course different from the ex post truncation of the dependent returns variable.
} 
full sample.

In sum, this paper makes several contributions. It highlights the message in Core (2006) and Kothari et al. (2005) that ex post trimming of extreme returns is an incorrect procedure for testing robustness of market efficiency or anomaly studies. The study demonstrates that ex post trimming of right skewed returns induces an alternative spuriously-shaped relation when returns skewness varies systematically with the accounting predictors. Finally the study highlights the importance of including adequate asset pricing controls and using the appropriate regression methods and test statistics to draw inferences.

Section 2 describes the sample selection and defines the variables used. Section 3 reports the main analysis on how truncation bias from ex post trimming of extreme returns creates a spurious inverted-U relation. Section 4 examines the robustness of anomalies in profit sample, and explores the effects of abnormal return measure, regression method and inadequate asset pricing controls on the truncation bias. Section 5 pursues sources for why loss firms tend to have extreme right skewness of returns. Section 6 concludes the paper.

\section{Sample Selection and Descriptive Statistics}

We describe sample selection in subsection 2.1. Subsection 2.2 examines the definition and measurement of the financial variables used. Subsection 2.3 describes the calculation of abnormal returns used later in the paper where portfolio returns and hedging profits are discussed.

\subsection{Sample Selection}

The sample covers NYSE, AMEX and NASDAQ firms with available data from July 
1964 to December 2002, from the intersection of CRSP and Compustat datasets. All observations are required to have sufficient financial data to compute net operating assets, accruals, earnings, firm size, the book-to-market ratio, and 11 month past returns. The last three variables are needed to compute the Daniel, Grinblatt, Titman, and Wermers (1997) three- factor characteristics adjusted abnormal returns.

KLW discuss several possible selection biases in anomalies research. First, most studies limit analyses to NYSE/AMEX firms and may depend on either ZLIST (from Compustat) or HEXCD (from CRSP) to identify the exchange listing. However, only EXCHCD (from CRSP) variable provides the right historical identification. They document that this subtle choice can affect the documented Accruals hedge returns. Second, the exclusion of firm-year observations in which year $t+1$ Earnings or Accruals are missing, which is imposed by some previous papers in the literature in order to perform the Mishkin (1983) test, can introduce a survivorship bias. A further selection bias involves excluding firm-year observations with missing returns during the BHAR accumulation period.

We use a procedure that avoids all three potential sample selection biases. We include firms on NASDAQ as well NYSE/AMEX, so there is no misidentification problem across exchange listing. The results here do not rely on the Mishkin (1983) test, so no constraint for the availability of future financial data is imposed in our test design. Finally, the portfolios examined in this study are rebalanced monthly, and so avoid the problems associated with the calculation of annual BHARs. In addition, since we do not use BHARs, we also avoid the measurement problems highlighted by Fama (1998) for long-term returns. ${ }^{5}$

\footnotetext{
${ }^{5}$ For several reasons (including non-normality and bad model problems), Fama (1998, p. 291) maintains that monthly returns are superior to longer horizon returns for asset pricing tests. He asserts (p. 285) that "formal inferences about long-term returns should be based on averages or sums of short-term abnormal returns (AARs or
} 


\subsection{Financial Variable Definition and Measurement}

Net operating assets are calculated as the difference between operating assets and operating liabilities following Hirshleifer et al (2004), where Operating Assets $_{t}=$ Total Assets $_{t}-$ Cash and Short Term Investment $t_{t}$ Operating Liabilities $_{t}=$ Total Assets $_{t}-$ Short Term Debt $t_{t}$ Long Term Debt $t_{t}$ - Minority Interest $t_{- \text {Preferred Stock }}-$ Common Equity $_{t}$

We calculate operating accruals using the indirect balance sheet approach (Sloan 1996) for all fiscal years in my sample, since the data coverage starts before 1987, when SFAS 95 was effective and cash flow from operations numbers are directly reported and available from Compustat (Hribar and Collins, 2002).

Accruals $_{b s}=(\Delta$ Current Assets $-\Delta$ Cash and Short Term Investment $)$

- (4Current Liabilities - AShort-term Debts - $\Delta$ Tax Payable) - Depreciation

Cash Flow from Operation = Operating Earnings - Accruals $_{\mathrm{bs}}$

Net operating assets, operating accruals, cash flow from operations (CFO) are scaled by the fiscal year beginning total assets (Compustat \#6). ${ }^{6}$ To avoid the extremely small denominator problem, we delete observations with lagged total assets smaller than one million dollars. When calculating NOA and Accruals, if short-term debt, tax payable, long-term debt, minority interest, or preferred stock has missing values, we treat these values as zeros to avoid unnecessary loss of observations.

We use the eleven-month intermediate return horizon starting 12 months through 2 months prior to the portfolio formation month as the measure of price momentum. Following the

CARs) rather than ... buy-and-hold abnormal returns (BHARs)" because the "bad-model errors in expected returns grow faster with the return horizon than the volatility of returns."

6 The main results of this paper are not affected by the choice of ending total assets or average total assets as deflators for Accruals and NOA. 
convention in the finance literature, for this variable we skip the month just prior to the testing month (which we control for separately).

\subsection{Calculation of Abnormal Returns:}

When measuring abnormal portfolio returns for computing profits from the trading strategy, we adopt the characteristics-adjustment approach proposed by Daniel et al. (1997) to control for the following asset pricing characteristics: size, book-to-market $(\mathrm{B} / \mathrm{M})$, and momentum, simultaneously to better isolate the anomalous effect investigated. The empirical evidence provided by Daniel and Titman (1997) suggests that characteristics provide better ex ante cross-sectional forecasts of future returns than do factor loadings.

Specifically, each month, the size-B/M-momentum benchmark portfolios $(5 * 5 * 5=125)$ are formed based on NYSE cutoff points. To calculate monthly characteristics-adjusted returns (hereafter 'abnormal returns'), we then subtract the equal weighted returns of the size-B/M-momentum benchmark portfolio to which the firm belongs from the raw buy and hold returns for each firm each month. To ensure the availability of the financial information, returns are matched with the financial data starting from the fifth month to the sixteenth month after fiscal year end.

\section{Truncation Bias from Trimming Extreme Returns Firms}

The ex post trimming of extreme observations from a right skewed return distribution induces a downward truncation bias in the mean returns of the trimmed sample. This is because the return distribution is left bounded at $-100 \%$ and truncation based on the least trimmed squares procedure predominantly removes the right tail and not as much of the left tail extreme observations. 
Consider the Accrual anomaly and the truncation of extreme positive returns. Suppose that the return skewness does not vary cross-sectionally with Accruals and the same return cut-off value is applied to truncate extreme positive return observations in every Accrual decile portfolio. Then, the portfolio with the highest density of large positive returns (i.e. lowest Accrual decile) will have the largest fraction of extreme positive returns eliminated and therefore experience the largest downward bias in returns. On the other hand, the portfolio with the lowest density of positive returns (highest Accrual decile) will have the smallest fraction of positive returns eliminated, and therefore experience the lowest downward bias in returns.

While every decile experiences a downward bias in returns with the above truncation procedure, the net effect of the anomaly can either be weakened, eliminated, or even reversed; see Figure 1 for the case of the weakened effect. However, the linear effect of Accruals on returns would still be preserved; see Core (2006). The same effect applies to the NOA and CFO anomalies.

\section{Insert Figure 1 Here}

Uneven truncation of return distributions by itself does not induce the inverse U-relation for the Accruals anomaly. The truncation needs to be applied to distributions that vary in right skewness with the predictive variable in a non-linear way. We will illustrate this by considering two sub-samples of firms, those with profits versus those with losses, where their returns-skewness variation with Accruals is different.

\subsection{The Monthly Return Distributions of Profit and Loss Firms}

Recent accounting literature highlights the significance of losses, particularly in recent years. The prevalence of losses has risen markedly from about 3\% of firms in the early 1960s to 
over $40 \%$ in 2000 among firms covered by COMPUSTAT. Moreover, prior literature suggests that the return distribution of loss firms differs in important ways from that of profit firms ${ }^{7}$.

As discussed in the introduction, the economic circumstances of loss firms lead to an expectation of high positive skewness, both because loss firms are likely to have high earnings volatility (and stock returns are bounded below by -100\%), and because such firms may in many cases be like lottery gambles in which there is a long upper tail of possible favorable outcomes.

Table 1 provides the descriptive statistics of monthly returns distribution for profit firms versus loss firms. The returns are measured from the fifth to the sixteenth month after the fiscal year end and the time series averages across the calendar month are reported. The monthly return distribution of loss firms is quite distinct from that of profit firms. The median return is $-1.60 \%$ for the loss sample, compared with $0 \%$ for the profit sample. The $95^{\text {th }}$ and $99^{\text {th }}$ percentiles of the return distribution for loss firms are $44.8 \%$ and $100.0 \%$ respectively, compared with $25.0 \%$ and 48.7\% for the profit firms. As expected, loss firms' returns have high variance $(8.5 \%$ for loss firms versus. 2.3\% for profit firms), and high positive skewness (5.84 for loss firms versus 3.39 for profit firms). Therefore, the return distribution of loss firms deviates from normality far more than that of profit firms in terms of skewness. ${ }^{8}$

Barberis and Huang (2008) model the behavior of investors whose preferences satisfy the cumulative prospect theory of Tversky and Kahneman (1992). Such investors have a strong desire to hold positively skewed portfolios, and may even hold undiversifed positions in positively skewed assets because of the overweighting in the tail of the probability distribution. It

\footnotetext{
7 Several authors document that the stock price behavior of loss firms differs significantly from that of profit firms. There is no significant contemporaneous return-earnings relation for losses (Hayn 1995), post-earnings announcement drift is weaker among loss than among profit firms (Narayanamoorthy, 2003), and the Accruals anomaly disappears in a loss sample (Dopuch et al. 2005). KLW observe that most firms with extreme positive BHARs experience poor financial performance (losses). In contrast, Beneish, Lee, and Tarpley (2001) find that an indicator variable for losses over the past four quarters negatively forecast returns only in a trimmed sample.

${ }^{8}$ Klein and Marquardt (2006) report evidence that the percentage of losses for U.S. firms is significantly related to accounting conservatism, Compustat coverage of small firms, real firm performance, and business cycle factors.
} 
is striking that loss firms offer returns with strong positive skewness.

$$
\text { Insert Table } 1 \text { Here }
$$

\subsection{Fama-Macbeth Regression Tests of the Sources of Truncation Bias}

Kothari et al. (2005) point out that these higher moments affect how trimming extreme observations affects the cross-sectional associations between information variables and future returns (p. 131) and even induce evidence to spuriously reject the null of no return predictability.

In this section, we perform Fama-Macbeth monthly cross-sectional regressions to investigate the relation between a loss indicator variable (Loss $=1$ if the firm experienced a loss, and 0 otherwise) and subsequent one year ahead returns subject to an extensive standard set of risk controls, in both the trimmed and the untrimmed samples.

Throughout the paper, for the untrimmed sample, we use the conventional Fama-Macbeth regression. For the trimmed sample, following KLW we apply the Least Trimmed Square (LTS) procedure to eliminate observations with the highest $1 \%$ squared residuals in each monthly regression; then Ordinary Least Square (OLS) regression is performed based on the trimmed sample to estimate the coefficients. The time series averages of the coefficients along with their $t$-statistics are reported as usual.

The asset pricing controls included in our Fama-Macbeth regression consist of size, B/M, intermediate 11-month returns (for the Jegadeesh and Titman (1993) momentum effect), one-month returns (for the Jegadeesh (1990) contrarian effect), and 3-year returns (using returns from month -36 to -13 for the DeBondt and Thaler (1985) long-term reversal effect).

Panel A of Table 2 reports the regression results with Loss added to the above asset pricing factors. Consistent with our conjecture that loss firms suffer from a stronger negative truncation 
bias on returns, Loss is a negative predictor of future returns with high significance $(t=-7.95)$ in the trimmed sample, but not in the untrimmed sample $(t=-1.59)$.

This evidence clearly suggests that truncation of extreme value observations reduces the average return on loss firms more than that on profit firms since the return distribution of loss firms is more positively skewed (with a fatter right tail) than that of profit firms. The seemingly highly significant "loss effect" in the trimmed sample is a spurious consequence of data truncation as pointed by Kothari et al. (2005).

Consistent with Knez and Ready (1997), the coefficient associated with the size variable becomes positive in this trimmed sample. We also find that there is no incremental long-run reversal effect for the trimmed sample.

$$
\text { Insert Table } 2 \text { Here }
$$

Panel B of Table 2 reports the regression results with the Accruals, NOA and CFO variables added. Consistent with Desai et al. (2004), Accruals loses significance when CFO is included in the regression. In contrast, NOA remains highly significant after controlling for CFO. Again, the Loss dummy is a strong negative predictor of future returns only for the trimmed sample, not for the untrimmed one.

\subsection{The Inverted-U Relation in the Trimmed Sample}

In this subsection, we explore how the truncation bias may induce the inverted-U relation between returns and Accruals or NOA when the return skewness varies with Accruals or NOA

3.3.1. The Severity of Truncation Bias Varies with Accounting Predictors

Earnings consist of the sum of Accruals and CFO, so when Earnings are low, Accruals and CFO tend to be low as well (Sloan 1996). Hirshleifer et al. (2004) document that there is also a 
monotonic positive relation between Earnings and NOA. Consequently, the frequency of losses is likely to be higher among low Accruals, NOA and CFO firms. Since loss firms tend to have higher skewed return distributions, it follows that we expect the truncation bias will be stronger in portfolios with low Accruals, NOA and CFO firms .

Table 3 reports the time series average of the frequency of losses in Accruals, NOA, and CFO deciles. Firms are separately ranked by these accounting variables into 10 equal deciles; low ranks contain firms with low values for these variables. The decrease in the frequency of losses along the lowest five decile portfolios is dramatic and monotonic. In the lowest Accruals, CFO and NOA decile portfolios respectively, the average frequency of losses is $42.2 \%, 58.6 \%$, and $39.6 \%$, which decreases to $12.4 \%, 9.3 \%$, and $13.2 \%$ for the fifth Accruals, CFO, and NOA deciles respectively. In contrast, the frequency of losses remains fairly constant and low (about 10-15\%) across the five highest deciles.

Insert Table 3 Here

\subsubsection{Loss Firms, Trimming, and the Inverted-U Relation}

Table 3 shows that the frequency of losses, and correspondingly return skewness, is greatest among the lowest five rank portfolios, and so trimming the sample exerts the strongest downward truncation bias on returns within the lowest five ranked portfolios. Therefore, the observed relation in the trimmed sample between the accounting variable ranks and future returns will depend on both the strength of the anomaly in the untrimmed sample, and on the truncation bias induced by trimming.

If the truncation bias is sufficiently strong for the lowest Accruals decile, the abnormal returns can actually turn negative with trimming. Since there are fewer loss firms among the 
higher rank portfolios, the high deciles are relatively undisturbed and will continue to demonstrate a negative relation with future stock returns. Consequently, an inverted-U relation between Accruals and NOA deciles and future abnormal returns should emerge in the trimmed sample, as illustrated in Figure 2.1 (the broken line). To summarize, the inverted U-shape truncation bias across the accounting predictive variables induces the inverted U-shape relation for returns with the accounting predictors in the trimmed sample. We test for this directly in subsection 4.4.

Figure 2 also helps explain two unexplained observations made by KLW. First, trimming has little impact on the high rank Accruals, NOA or CFO deciles since the frequency of losses and associated truncation bias across the highest five deciles are small and approximately constant (Figure 2.1).

Second, Figure 2.2 explains why a stronger CFO effect will be observed for the trimmed sample (KLW 2005). The truncation bias is stronger in low CFO deciles, instead of in high CFO deciles. Consequently, the truncation bias induces a more positive relation between CFO decile and future stock returns in the trimmed sample, which exaggerates the CFO anomaly. The outcome combining the CFO anomaly with the truncation bias appears as the steeper but bended line in Figure 2.2.

Insert Figure 2 Here

\section{Robustness of Anomalies in Profit Firms, Effects of Regression Method, and Asset Pricing Controls}

Since we expect the truncation bias to be much weaker among profit firms than among loss firms, there is reason to expect anomalies among profit firms to be robust to the truncation 
bias. Therefore, in this section we investigate whether, among profit firms, return truncation results in an inverted-U relation between the Accruals/NOA and future stock returns, or whether the standard monotonicity of these return-accounting predictor relations remains.

KLW adopt a pooled cross-sectional and time-series OLS regression method, and only size is used as the asset pricing control for abnormal returns. Therefore, before we conduct our analysis on profit firms only, we first evaluate whether the inverted U-shape relation from truncation bias in the general sample of firms is sensitive to the regression method and asset pricing benchmarks used to measure abnormal returns. We examine the effects of using long-horizon buy-and-hold abnormal returns versus an alternative measurement method for abnormal returns in subsection 4.1. The differences between the pooling regression and the Fama-Macbeth cross-sectional regression method is in subsection 4.2. The effects of incorporating a more extensive set of controls following the asset pricing literature is discussed in subsection 4.3. Finally, we evaluate the robustness of the anomalies for only profit firms in subsection 4.4.

\subsection{Long-horizon BHARs versus Monthly Returns with Size Characteristics Adjustment}

We now evaluate how the use of pooling regression versus Fama-Macbeth monthly regression affects the inverted-U shape. Table 4 replicates Tables 3 and 6 of KLW using the pooling OLS regression method but with the following differences in procedure. To avoid the bad model problems associated with long-horizon buy-and-hold returns (Fama 1998), we do not use annual buy-and-hold returns adjusted for size. Instead, we use monthly raw returns as the dependent variable and control for size using the firm's natural log of market value of equity as an independent variable in the regressions (Daniel and Titman 1997). Another advantage of using 
monthly return instead of annual return is that the distribution of monthly returns is less right skewed, and therefore less subject to the truncation bias. For the remaining explanatory variables, following KLW we set the indicator variable DL_acc (cfo, noa) to 1 if the firm is in the lowest Accruals (CFO, NOA) decile in a particular calendar month; 0 otherwise. The indicator variable DH_acc (cfo, noa) is set to 1 if the firm is in the highest Accruals (CFO, NOA) decile in a particular calendar month; 0 otherwise. D2_acc (cfo, noa) to D9_acc (cfo, noa) are indicator variables set to one if the firm is in the corresponding Accruals (CFO, NOA) deciles. Those indicator variables represent the difference in returns between the test portfolio and the base portfolio (deciles 4 and 5).

Consistent with KLW, there is an inverted-U relation for Accruals and NOA (Panels A and C respectively). The coefficients associated with DL_acc (DL_noa) and DH_acc (DH_noa) are $-0.0115(-0.0055)$ and $-0.0138(-0.0170)$ respectively. Panel B demonstrates that the CFO effect is much stronger for the five lowest CFO deciles in the trimmed sample.

As illustrated in Figure 2, the differences in coefficients associated with the five highest Accruals, CFO, and NOA decile indicator variables between trimmed and untrimmed samples are much smaller than those for the five lowest Accruals, CFO, and NOA decile indicator variables.

$$
\text { Insert Table } 4 \text { Here }
$$

\subsection{Pooling Regression versus Fama-Macbeth Regression}

In the finance literature, the Fama-Macbeth regression method is commonly used to investigate cross-sectional return predictabilities (see Campbell, Lo, and MacKinlay 1997). In a typical asset pricing application of the Fama-Macbeth method, researchers regress monthly 
equity returns on annual values of lagged firm-level financial variables.

The Fama-Macbeth approach has the advantage of addressing "time effects," in which the regression residuals of a given time period may be correlated across firms. Fama-Macbeth standard errors are more efficient than the OLS estimates (Petersen 2009). ${ }^{9}$

Monthly returns are regressed on our test variables, the decile ranks of either Accruals, CFO, or NOA, in both trimmed and untrimmed samples, and the time series averaged coefficients along with their t-statistics are reported in Tables 5 and 6 . We include only size as a control variable in Table 5 to facilitate comparison of results with KLW. In Table 6, we include additional standard asset pricing controls to evaluate robustness with respect to additional controls.

The empirical results in Table 5 differ from those in Table 4 in several ways. The $t$-statistics associated with the coefficients are much smaller in Table 5 than in Table 4 . The t-statistics in Table 5 are calculated from the time-series sample of 462 monthly cross-sectional regression coefficients, which is much fewer than the number of total observations (about 1.6 million) from which $t$-statistics of the pooling OLS method are calculated in Table 4. The inference about NOA is also different. In the trimmed sample, the coefficients associated with the lowest four NOA deciles are not significantly different from zero in Table 5, whereas they are highly significant for the lowest three NOA declies in Table 4.

In sum, trimming does not reshape the pattern between Accruals or NOA and returns when Fama Macbeth regression procedure is used as much as it does when the pooling regression method is used. The Fama-Macbeth procedure has two advantages over the simple pooled OLS regression. It avoids the biased test statistics from cross-sectional correlation of residuals that

\footnotetext{
${ }^{9}$ A few authors suggest adjusting the Fama-Macbeth standard error for the estimated first order auto-correlation of the estimated slope coefficients to account for any possible firm effect (Newey-West adjusted standard error).

Petersen (2009) shows that the adjustment may not work under certain circumstances.
} 
may be present in the OLS pooled regression. Especially relevant for the current application, the Fama-Macbeth procedure also reduces the likelihood that an extreme monthly return would exert an undue influence on the regression estimates since the coefficients are averaged over all monthly regressions.

\section{Insert Table 5 Here}

\subsection{The Importance of Adequate Asset Pricing Controls}

Sloan (1996) and many other Accruals anomaly studies (e.g. Xie (2001) and Collins and Hribar (2002)), including KLW, use decile size-adjusted returns to measure abnormal returns. In the last decade, however, research in accounting and finance has identified other return predictors that are not subsumed by the size effect. In consequence, it has become standard in abnormal returns studies in the asset pricing literature to control for other known return predictors.

In Table 6, we repeat Table 5 by adding book-to-market, past one-month return, past one year return (excluding latest month), and past three year returns (excluding the latest year). ${ }^{10}$ Panel A of Table 6 shows that including standard asset pricing controls greatly weakens the inverted-U relation for Accruals in the trimmed sample.

In addition, including these controls restores the monotonic relation across NOA decile dummies even in the trimmed sample, although the NOA effect is still weaker in the trimmed sample (Panel C) than in the untrimmed sample, which is not surprising. The greater robustness of the NOA anomaly with respect to trimming relative to the Accruals anomaly is consistent with previous finding that the NOA anomaly is stronger than the Accruals anomaly, especially on the

\footnotetext{
${ }^{10}$ Khan (2006) argues that the Accruals effect disappears when a four factor model is used to control for risk. The four factors include size, book-to-market, and the two factors decomposed from the market factor as introduced by Campbell and Voulteenaho (2004). These two additional factors represent news about future dividends and news about future discount rate. Untabulated results show that the Campbell and Voulteenaho factors themselves are not significant, and therefore we do not consider these factors as additional controls.
} 
long side (Hirshleifer et al. 2004). In consequence, the truncation bias is not strong enough to dominate the NOA anomaly in any range of the deciles.

The above results also demonstrate that when we correct for risk using more extensive controls, we strengthen the anomalous Accruals or NOA effects rather than mitigate them. This evidence is consistent with the hypothesis that the equity market does not properly price the information in Accruals or NOA.

In sum, a failure to include standard asset pricing controls and improper measurement of returns further contributes to the inverted-U relation, above and beyond the direct effect of trimming.

$$
\text { Insert Table } 6 \text { Here }
$$

\subsection{Truncation Bias among Profit Firms}

In section 3, we argued that an inverted-U relation for the Accruals and NOA anomaly in a trimmed sample can result from the combination of a genuine Accruals or NOA anomaly that exists in an untrimmed sample, and a spurious truncation bias. To further test this conjecture, we analyze the skewness of returns across profit firms versus the full sample of firms in Table 7, and the magnitude of the truncation bias in Table 8. Then, we run both the OLS and the LTS regressions in the profit-only sample in Table 9 for the following two reasons.

First, we expect the truncation bias to be much weaker in the profit sample, since as argued earlier profit firms should be less right-skewed in their return distributions. Second, numerous studies (Dopuch et al. 2005, Zhang and Lin 2007) find that Accruals anomaly is present in only profit firms. Taken together, in the profit sample, the truncation bias may not be strong enough to dominate the Accruals effect. Therefore, we would not expect to see the inverted-U relation 
between Accruals and returns even with trimming.

Table 7 presents the return skewness across Accruals, CFO and NOA deciles for the full sample versus the profit only sample. Consistent with our expectation that the profit-only sample is less subject to the truncation bias, we find that the differences in skewness between the highest and the lowest Accruals, CFO and NOA deciles reduce by more than half from 0.75, 0.85 and 0.94 in the full sample to $0.26,0.42$ and 0.41 in the profit sample respectively.

\section{Insert Table 7 Here}

We examine the magnitude of the truncation bias across deciles in Table 8. We report the number of monthly return observations that are trimmed using the LTS procedure for each decile portfolio, grouped by positive abnormal returns versus negative abnormal returns. We compare the truncation bias across deciles for the general sample on the left-hand side of the table versus the profit sample on the right-hand side.

\section{Insert Table 8 Here}

It is striking that many more extreme positive abnormal return observations are deleted than extreme negative observations, by an order of magnitude larger, across all three accounting predictors. It is also remarkable that the number of observations deleted exhibits an inverted U-shape across the deciles for both the positive and negative extreme observations for Accruals and NOA. Similar patterns are observed for the magnitude of the deleted observations.

Because the number of extreme positive return observations dominates the number of extreme negative return observations, the net effect of trimming varies systematically according to the inverted U-shape across the deciles. For example, much larger positive returns are trimmed from both the lowest and highest Accrual deciles than from the middle groups. Furthermore, the lowest decile suffers the greatest loss of returns from trimming, the truncation bias, than the 
highest decile.

The truncation bias is much more severe for the full sample than for the profit sample. For example, trimming induced a huge drop in total hedge returns in the full sample, but increases the total abnormal returns between top and bottom deciles in the profit sample. Therefore the net truncation bias between top and bottom deciles is downwards and very large in magnitude in the full sample whereas the net truncation bias is actually upwards albeit smaller in magnitude for the profit sample. In absolute values, the order of magnitude of the truncation bias is 32 times larger in the full sample than in the profit sample. Therefore, it would not be surprising that for the profit sample anomalies might survive trimming of observations. We check whether this is the case using the regression tests for the profit sample next.

The regression results for the profit-only sample are presented in Table 9. Panel A shows that the lowest Accruals decile is associated with positive abnormal future returns after controlling for the standard asset pricing controls for both the trimmed and the untrimmed samples. This is consistent with our hypothesis that in a sample in which the truncation bias is largely reduced, the Accruals anomaly is robust to trimming. Moreover, the Accruals anomaly in Table 9 is much stronger than that in Table 6 even for the untrimmed sample.

For the CFO effect (Panel B), the differences in the coefficients associated with DL_cfo between the trimmed sample and the untrimmed sample are much less dramatic than those in Panel B of Table 5 (0.17 in Table 7 vs. 0.76 in Table 5). The finding is also consistent with the argument that the truncation bias is less severe in the profit sample since, as argued earlier, truncation bias tend to exaggerate instead of weaken the CFO effect in the trimmed sample.

$$
\text { Insert Table } 9 \text { Here }
$$

The coefficients associated with the NOA decile dummies decrease monotonically across 
deciles in both the untrimmed and the trimmed samples for the profit only sample (Panel C). DL_noa are $0.0040(t=5.40)$ and $0.0032(t=4.82)$ respectively. In comparison, DL_noa are $-0.0055(t=-11.67)$ in Table 4 (pooling OLS, the replication of KLW), $-0.0016(t=-1.06)$ in Table 5 (Fama-Macbeth regression with size control only) and $0.0024(t=2.33)$ in Table 6 (Fama-Macbeth regression with the more factor asset pricing control) for the trimmed sample (LTS) respectively.

In sum, the inverted-U relation when data is trimmed is a consequence of a non-random truncation bias in samples with highly skewed returns. The return distribution of loss firms are more skewed than that of profit firms, and that low Accruals or NOA firms are more likely to be loss firms than high Accruals or NOA firms. The robustness of the Accruals and NOA anomalies with respect to trimming for profit firms also indicates that the anomalies are more robust and pervasive than suggested by KLW; it is not the case that these effects are driven by only a few firms. Finally, the spurious inverted-U relation is also partly due to inadequate asset pricing controls and the failure to address cross-sectional correlation of residuals in the regressions. ${ }^{11}$

\section{Sources of Return Right Skewness in Loss Firms}

Although loss observations only account for $21 \%$ of the sample, loss firms account for $70 \%$ of deleted observations from the LTS procedure (returns exceeding approximately 100\%). What are the economic reasons why extreme large positive returns tend to be concentrated among loss

11 KLW suggest that their results are robust with respect to using logged buy and hold annual returns. Taking logarithms shrinks extreme large positive numbers, and exaggerates large negative numbers. Therefore, the effect of using log BHAR is similar to the effect obtained using the LTS trimming method since returns are bounded below at $-100 \%$, and the trimming is more likely to eliminate extreme positive observations. It is common to use simple returns when studying cross-section effects of asset returns, whereas continuous compounded returns (logged return) are considered when the temporal behavior of returns is the focus of interest (Campbell et al. 1997, p12).

Furthermore, the simple return on a portfolio of assets is the simple weighted average of the individual asset returns. Logged returns do not share this convenient property since the log of a sum is not the same as the sum of logs (Campbell et al. 1997). When logged returns are used, the regression coefficients do not have a clear interpretation as portfolio returns, and therefore logged returns are not commonly used. 
firms? To answer this, we focus next on the characteristics of loss firms that experience extreme positive returns.

Beneish et al. (2001) document the characteristics of extreme positive return observations in a pooled sample containing both profit and loss firms. They show that such observations are associated with younger, lower-priced and smaller firms with more volatile returns, higher trading volume and more positive price momentum. They also notice that extreme positive return observations tend to be loss firms.

Knez and Ready (1997) proposed the "Turtle Egg” hypothesis to explain why extreme large return observations are concentrated in small firms. The name comes from the fact that mother sea turtles lay many eggs, but few hatch and even fewer make it to the ocean; but those that succeed can grow to be quite large. In the same way, small negative earnings firms often do not survive, but some that do may ultimately become large.

Knez and Ready (1997) provide initial evidence that a larger fraction of young firms than old firms experience large positive returns, consistent with the turtle egg story. The hypothesis also predicts that such observations should concentrate in new industries in which there is a chance of a big success. One might also expect such observations of big success during periods of market booms.

\section{Insert Table 10 Here}

Table 10 provides the cross-industry distribution of extreme winner loss firms. We adopt the Fama and French (1997) 48-industry classification scheme. We find that such observations mainly concentrate in the high-tech industries such as Medicine, Drugs, Computer, Chips, Telecom and also in the Energy industries, consistent with the turtle egg hypothesis.

Figure 3 illustrates the time series distribution of extreme winner loss firms from 1968 to 
2002. The frequency of such observations increases dramatically during the second half of the sample, especially after 1997, peaks at around 2000, then drops thereafter. The pattern matches the rise and fall in the prices of technology stocks, the "tech bubble." The pattern also helps explain why the inverted-U relation is stronger in the KLW sample than in our sample. Their sample coverage starts from 1987, whereas ours cover a longer time series, beginning in 1964 .

Insert Figure 3 Here

\section{Conclusion}

Statistical theory teaches that it is invalid to draw inferences from a sample that is selected based upon the values of the dependent variable. Researchers in many sciences take special pains to avoid post-selection bias. Most researchers argue that outliers should only be removed when they represent data errors (Core 2006). As emphasized in the context of stock return studies by Kothari, et al. (2005), deleting observations with extreme returns induces biased inferences about return predictability.

In a recent paper, KLW draw some strong economic inferences about behavioral approaches to the Accruals and NOA anomalies based upon a problematic procedure. This is to artificially induce a selection bias by trimming extreme observations of the dependent variable, returns. After trimming, they find an inverted-U relation between Accruals or NOA and subsequent one-year abnormal returns. KLW argue that this finding rejects psychological explanations for these anomalies.

We show that this inverted-U relation is a spurious consequence of the return truncation bias of Kothari, Et al. (2005); in addition, inadequate risk (asset pricing) controls further contributes to the inverted-U relation. We find that low Accruals or NOA firms are disproportionately loss 
firms, which have greater positive skewness than profit firm, therefore are more likely to suffer from truncation bias. In contrast, in the upper five deciles of Accruals and NOA, there is relatively little truncation bias. Thus, an inverted-U relation occurs after trimming.

Our results, together with Kothari et al. (2005) demonstrate that researchers should be very cautious in ex post trimming extreme return observations unless it is believed that such observations are due to data error. Such procedure can either spuriously induce evidence against efficient market hypothesis (Kothari et al. 2005) or evidence against behavioral explanations (KLW). 


\section{References}

Ali, A., Hwang, L., Trombley, M., 2000. Accruals and Future Stock Returns: Tests of the Naïve Investor Hypothesis, Journal of Accounting, Auditing and Finance 15, 161-181.

Ali, A., Chen, X., Yao, and Tong T., 2008. Do Mutual Funds Profit from the Accruals Anomaly? Journal of Accounting Research 46, 1-26.

Barberis, N., M, Huang., 2008. Stocks as Lotteries: the Implications of Probatility Weighting for Security Prices. American Economic Review 98, 2066-2100.

Beneish, M., Lee., C., and Tarpley, R., 2001. Contextual Fundamental Analysis through the Prediction of Extreme Returns. Review of Accounting Studies 6, 165-189.

Bradshaw, M., Richardson, S., Sloan, R., 2000. Do Analysts and Auditors Use Information in Accruals? Journal of Accounting Research 39, 45-74.

Campbell, J., Andrew, L., and MacKinlay, C., 1997. The Econometrics of Financial Markets, Princeton University Press: Princeton, NJ.

Campbell, J., and Vuolteenaho, T., 2004. Bad Beta, Good Beta. American Economic Review 94, 1249-1275.

Carhart, M., 1997. On Persistence in Mutual Fund Performance. Journal of Finance 52, 57-82.

Core, J., 2006. Discussion of an Analysis of the Theories and Explanations Offered for the Mispricing of Accruals and Accrual Components. Journal of Accounting Research 44, 341-350.

Collins, D., Gong, J., and Hribar, P., 2003. Investor Sophistication and the Mispricing of Accruals. Review of Accounting Studies 8, 251-276.

Collins, D., and Hribar, P., 2002. Errors in Estimating Accruals: Implications for Empirical Research, Journal of Accounting Research 40, 105-134.

Daniel, K., Grinblatt, M., Titman, S., and Wermers, R., 1997. Measuring Mutual Fund Performance with Characteristic-based Benchmarks, Journal of Finance 52, 1035-1058.

Daniel, K. and Titman, S., 1997. Evidence on the Characteristics of Cross-Sectional Variation in Common Stock Returns. Journal of Finance, 52, 1-33.

DeBondt, W., and Thaler, R., 1985. Does the Stock Market Overreact? Journal of Finance 40, 793-805.

Dechow, P., and Ge., W., 2006. The Persistence of Earnings and Cash Flows and the Role of Special Items: Implications for the Accrual Anomaly. Review of Accounting Studies 11, 
253-296.

Dechow, P., Richardson, S., and Sloan, R., 2008. The Persistence and Pricing of the Cash Component of Earnings Journal of Accounting Research 46, 537-566.

Dopuch, N., Seethamraju., and Xu., W., 2005. The Pricing of Accruals for Profit and Loss Firms. Working paper, Washington University.

Desai, H., Rajgopal, S., and Venkatachalam, M., 2004. Value-Glamour and Accruals Mispricing: One Anomaly or Two? Accounting Review 79, 355-385.

Fairfield, P., Whisenant J., and Yohn, T., 2003. Accrued Earnings and Growth: Implications for Future Profitability and Market Mispricing. Accounting Review 78, 353-371.

Fama, E., and French, K., 1992. The Cross-section of Expected Stock Returns. Journal of Finance 46, 427-466.

Fama, E., and French, K., 1997. Industry Costs of Equity. Journal of Financial Economics 43, 153-193.

Fama, E., and MacBeth, J., 1973. Risk, Return and Equilibrium: Empirical Tests. Journal of Political Economy 81, 607-636.

Fama, E., 1998. Market Efficiency, Long-Term Returns, and Behavioral Finance. Journal of Financial Economics 49, 283-306.

Hayn C., 1995. The Information Content of Losses. Journal of Accounting and Economics 20, 125-154.

Hirshleifer, D., and Teoh, S., 2003. Limited Attention, Information Disclosure, and Financial Reporting. Journal of Accounting and Economics 36, 337-386.

Hirshleifer, D., Hou, K., Teoh, S. and Zhang, Y., 2004. Do Investors Overvalue Firms with Bloated Balance Sheets? Journal of Accounting and Economics 38, 297-331.

Hribar, P., and Collins, D., 2002. Errors in Estimating Accruals: Implications for Empirical Research. Journal of Accounting Research 40, 105-134.

Jegadeesh, N., 1990. Evidence of Predictable Behavior of Security Returns. Journal of Finance 45, 881-898.

Jegadeesh, N., and Titman S., 1993. Returns to Buying Winners and Selling Losers: Implications for Stock Market Efficiency, Journal of Finance 48, 65-91.

Joos, P., and Plesko, G., 2005. Valuing Loss Firms. Accounting Review 80, 847-871 
Khan, M., 2008. Are Accruals Really Mispriced? Evidence from Tests of an Intertemporal Capital Asset Pricing Models. Journal of Accounting Economics 45, 55-77.

Klein, A., and Marquardt., C., 2006. Fundamentals and Accounting Losses. Accounting Review 81, 179-206.

Knez, P. and Ready, M., 1997. On the Robustness of Size and Book-to-Market in Cross-Sectional Regressions. Journal of Finance 101, 1355-1382.

Kothari., S., Sabino, J., and Zach, T., 2005. Implications of Survival and Data Trimming for Tests of Market Efficiency. Journal of Accounting and Economics 39, 129-161.

Kraft, A., Leone, A., and Wasley, C., 2005. Research Design Issues and Related Inference Problems Underlying Tests of the Market Pricing of Accounting Information. Simon School Working Paper No. FR 04-15. Available at SSRN: http://ssrn.com/abstract=576183

Kraft, A., Leone, A., and Wasley, C., 2006. An Analysis of the Theories and Explanations Offered for the Mis-Pricing of Accruals and Accrual Components. Journal of Accounting Research 44, 297-339.

Levi, S., 2008. Voluntary Disclosure of Accruals in Earnings Press Releases and the Pricing of Accruals. Review of Accounting Studies 13, 1-21.

Louis, H., Robinson, D., and Sbaraglia, A., 2008. An Integrated Analysis of the Association between Accrual Disclosure and the Abnormal Accrual Anomaly. Review of Accounting Studies 13, 23-54.

Mushruwala, C., Rajgopal, S., and Shevlin, T., 2006. Why is the Accrual Anomaly not Arbitraged Away? The Role of Idiosyncratic Risk and Transaction Costs, Journal of Accounting and Economics 42, 3-33.

Petersen, Mitchell A., 2009. Estimating Standard Errors in Finance Panel Data Sets: Comparing Approaches, Review of Financial Studies 22, 435-480.

Sloan, R., 1996. Do Stock Prices Fully Reflect Information in Accruals and Cash Flows about Future Earnings? The Accounting Review 71, 289-315.

Teoh, S., Welch, I., and Wong, T. J., 1998a. Earnings Management and the Long Run Market Performance of the Initial Public Offering. Journal of Finance 53, 1935-1974.

Teoh, S., Welch, I., and Wong, T. J., 1998b. Earnings Management and the Underperformance of Seasoned Equity Offerings. Journal of Financial Economics 51, 63-99.

Teoh, S., and Wong, T., 2002. Why New Issue and High-Accrual Firms Underperform: The Role of Analysts’ Credulity. Review of Financial Studies 15, 869-900. 
Tversky, A., and Kahneman, D.,1973. Availability: A Heuristic for Judging Frequency and Probability. Cognitive Psychology, 5, 207-232.

Xie, H., 2001. The Mispricing of Abnormal Accruals. The Accounting Review 76, 357-373.

Zach, T., 2002. Inside the “Accrual Anomaly”, University of Washington, working paper.

Zhang, H., and Shi, L., 2007. Can the Earnings Fixation Hypothesis Explain the Accrual Anomaly? (February 2007). Available at SSRN: http://ssrn.com/abstract=965601 
Future Stock Returns

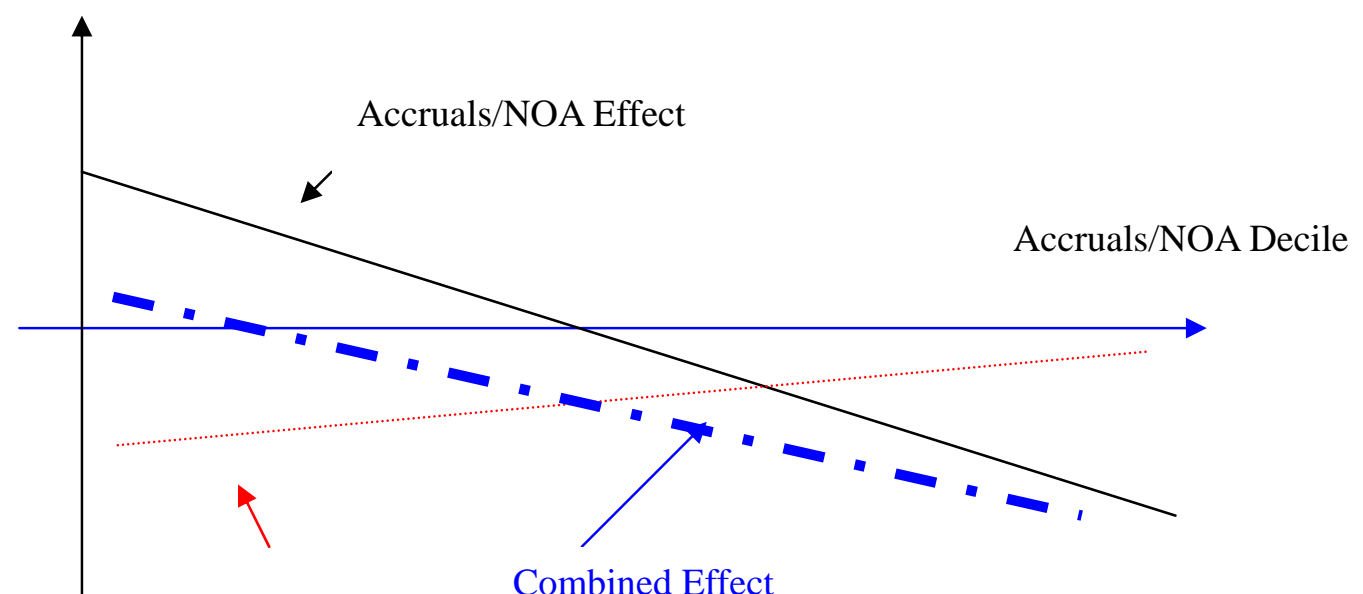

Truncation Bias Effe

Figure 1.1 The Effect of Truncation Bias on the Accruals or NOA Anomaly if Return Skewness unrelated to Accruals/NOA Declie Ranks

Future Stock Returns

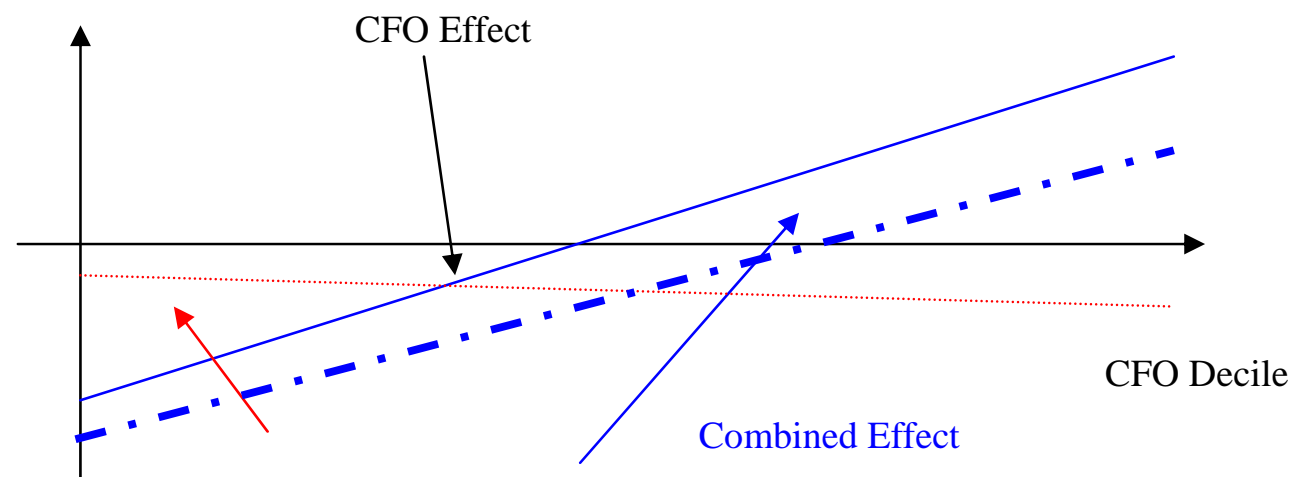

Truncation Bias Effect

Figure 1.2 The Effect of Truncation Bias on the CFO Anomaly if Return Skewness unrelated to CFO Decile Ranks 
Future Stock Returns

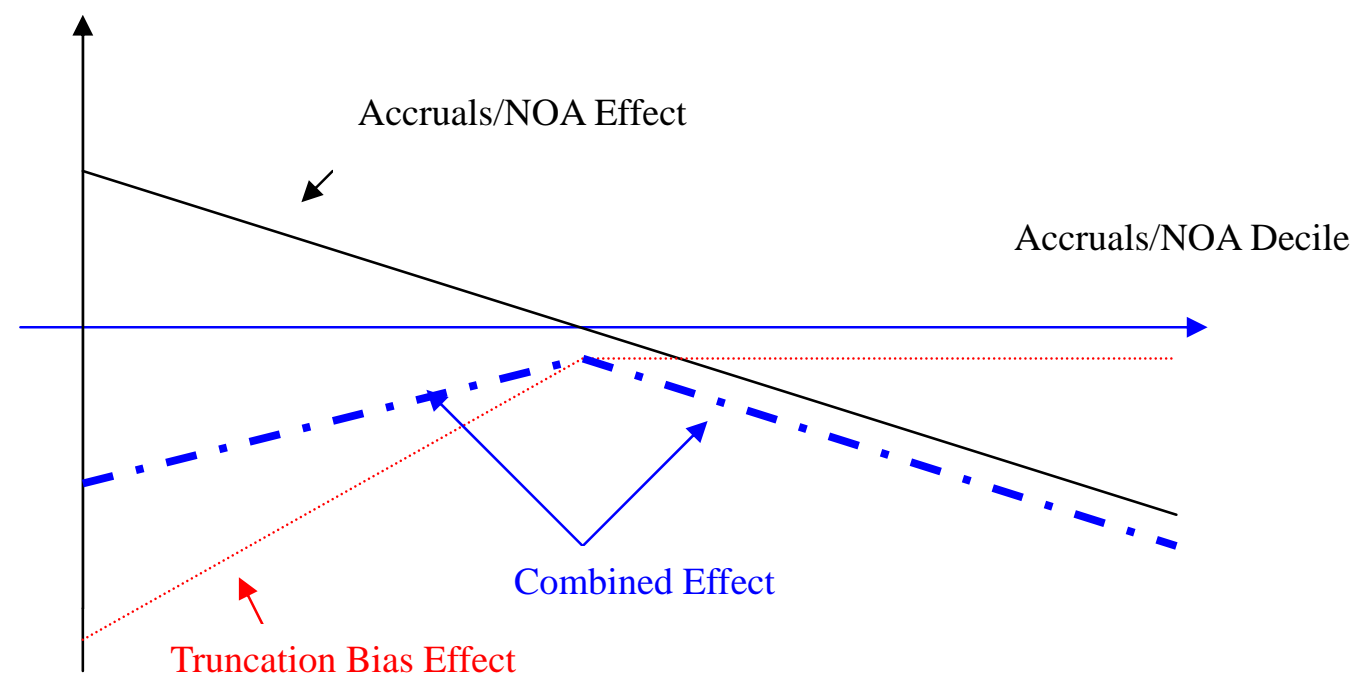

Figure 2.1 The Effect of Truncation Bias on the Accruals or NOA Anomaly when Return Skewness varies with Accruals or NOA Decile Ranks

Future Stock Returns

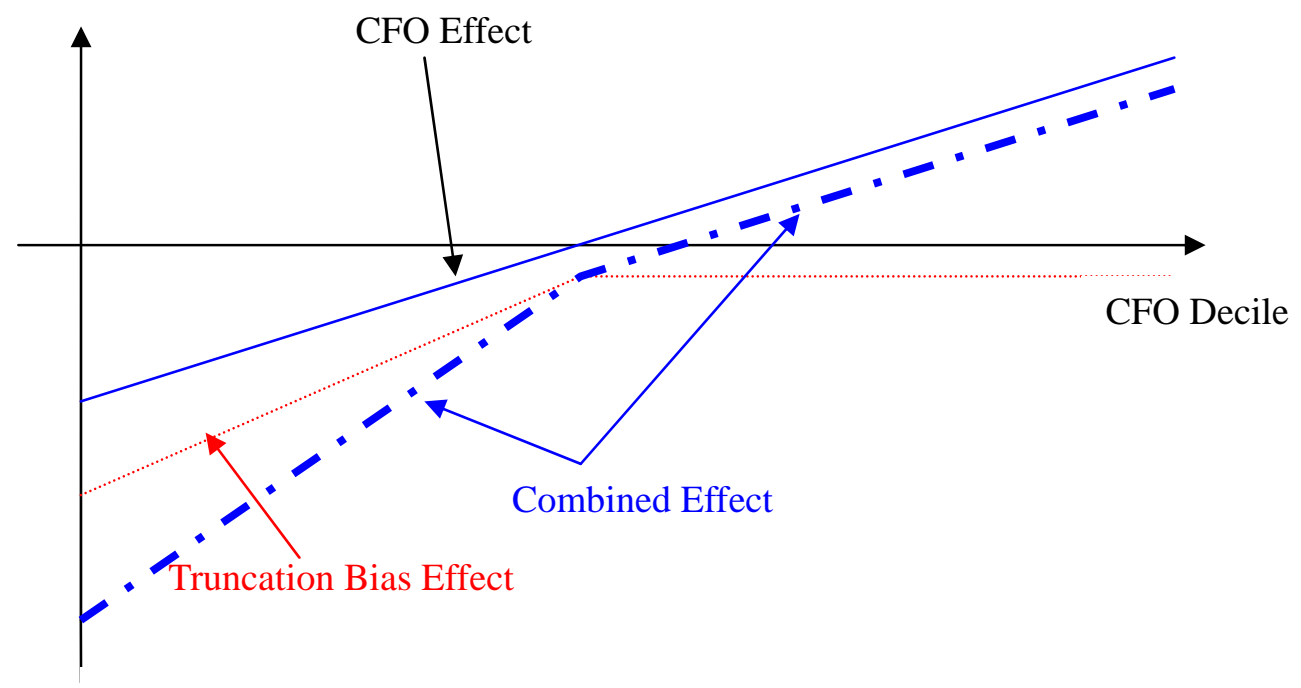

Figure 2.2 The Effect of Truncation Bias on the CFO Anomaly when Return Skewness varies with CFO Decile Ranks 
Time Distribution of Loss Firms with Extreme Large Monthly Returns $(>100 \%)$ by Year

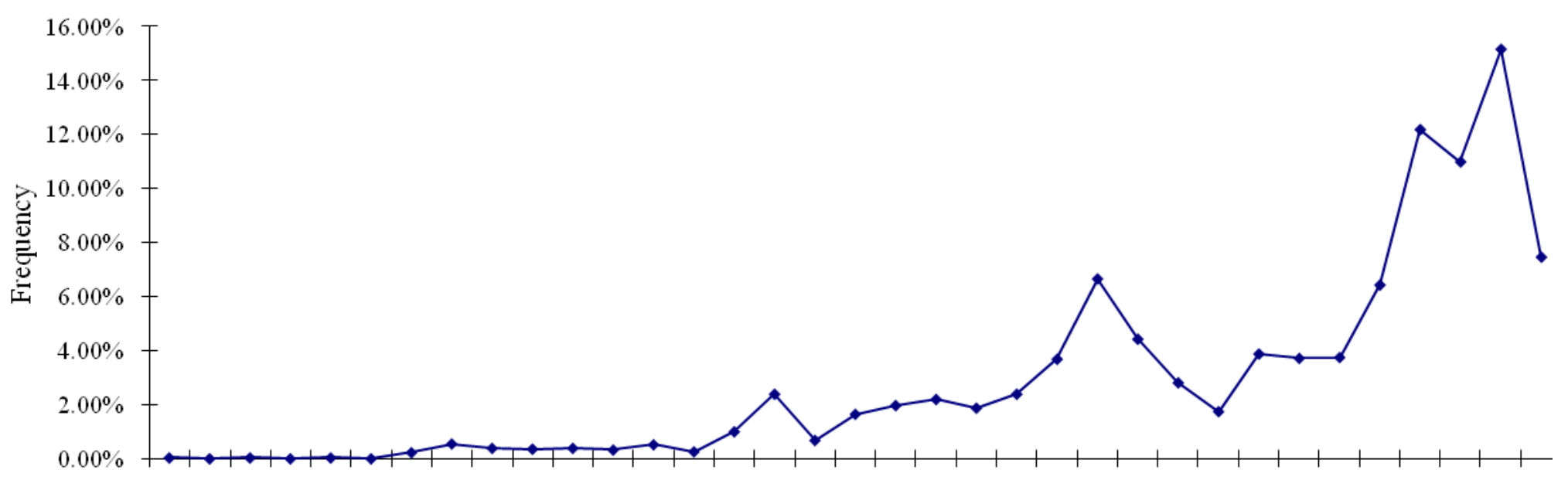

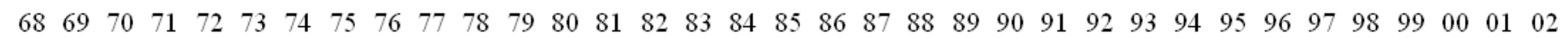

$\rightarrow \% \%$ obs

Figure 3: Time Distribution of Loss Firms with Extreme Large Monthly Returns ( $>100 \%)$ by Year

\begin{tabular}{ccccccccccccccccc}
\hline Year & 1968 & 1970 & 1972 & 1974 & 1975 & 1976 & 1977 & 1978 & 1979 & 1980 & 1981 & 1982 & 1983 & 1984 & 1985 & 1986 \\
\#obs & 1 & 1 & 1 & 7 & 17 & 12 & 11 & 12 & 10 & 16 & 8 & 31 & 74 & 21 & 51 & 61 \\
\%obs & $0.03 \%$ & $0.03 \%$ & $0.03 \%$ & $0.23 \%$ & $0.55 \%$ & $0.39 \%$ & $0.35 \%$ & $0.39 \%$ & $0.32 \%$ & $0.52 \%$ & $0.26 \%$ & $1.00 \%$ & $2.39 \%$ & $0.68 \%$ & $1.65 \%$ & $1.97 \%$ \\
\hline Year & 1987 & 1988 & 1989 & 1990 & 1991 & 1992 & 1993 & 1994 & 1995 & 1996 & 1997 & 1998 & 1999 & 2000 & 2001 & 2002 \\
\#obs & 68 & 58 & 74 & 114 & 206 & 137 & 87 & 54 & 120 & 115 & 116 & 199 & 377 & 340 & 469 & 231 \\
\%obs & $2.19 \%$ & $1.87 \%$ & $2.39 \%$ & $3.68 \%$ & $6.65 \%$ & $4.42 \%$ & $2.81 \%$ & $1.74 \%$ & $3.87 \%$ & $3.71 \%$ & $3.74 \%$ & $6.42 \%$ & $12.17 \%$ & $10.97 \%$ & $15.13 \%$ & $7.45 \%$ \\
\hline
\end{tabular}




\section{TABLE 1}

Distribution of Monthly Returns (One Year Ahead) for Profit vs. Loss Firms

\begin{tabular}{|c|c|c|c|c|c|c|c|c|c|c|}
\hline \multicolumn{11}{|c|}{ Panel A: Profit Firms } \\
\hline MIN & $1 \%$ & $5 \%$ & $10 \%$ & $25 \%$ & MEDIAN & $75 \%$ & $90 \%$ & $95 \%$ & $99 \%$ & MAX \\
\hline \multirow[t]{3}{*}{$-98.10 \%$} & $-33.30 \%$ & $-19.60 \%$ & $-13.90 \%$ & $-6.30 \%$ & $0.0 \%$ & $7.4 \%$ & $16.9 \%$ & $25.0 \%$ & $48.7 \%$ & $1400.0 \%$ \\
\hline & MEAN & & VARIANCE & & SKEWNESS & & KURTOSIS & & & \\
\hline & $1.28 \%$ & & 0.023 & & 3.39 & & 119 & & & \\
\hline \multicolumn{11}{|c|}{ Panel B: Loss Firms } \\
\hline MIN & $1 \%$ & $5 \%$ & $10 \%$ & $25 \%$ & MEDIAN & $75 \%$ & $90 \%$ & $95 \%$ & $99 \%$ & MAX \\
\hline \multirow[t]{3}{*}{$-97.10 \%$} & $-52 \%$ & $-33 \%$ & $-25 \%$ & $-13.30 \%$ & $-1.60 \%$ & $10 \%$ & $28.00 \%$ & $44.80 \%$ & $100 \%$ & $1900 \%$ \\
\hline & MEAN & & VARIANCE & & SKEWNESS & & KURTOSIS & & & \\
\hline & $0.91 \%$ & & 0.085 & & 5.84 & & 148 & & & \\
\hline
\end{tabular}

Note:This table reports the return distribution statistics for profit vs. loss firms for the pooled sample. The monthly returns are measured from the fifth to the sixteenth month after the fiscal year end. Mean, variance, skewness and kurtosis are also provided for each sample. 


\section{TABLE 2}

Fama Macbeth Regression of Returns of Size, B/M, One Month Reversal, Twelve Month Momentum, Thirty Six Month Reversal, Accruals, Cash Flow From Operations, NOA and LOSS Dummy

\begin{tabular}{|c|c|c|c|c|c|c|c|c|c|}
\hline $\begin{array}{l}\text { Panel A: } \\
\text { intercept }\end{array}$ & Ln(size) & $\ln (\mathbf{b} / \mathbf{m})$ & $\operatorname{ret}(-1:-1)$ & $\operatorname{ret}(-12:-1)$ & $\operatorname{ret}(-36:-13)$ & LOSS & & & \\
\hline \multicolumn{10}{|c|}{ OLS (Ordinary Least Square) } \\
\hline 0.0291 & -0.0013 & 0.0032 & -0.0698 & 0.0053 & -0.0023 & -0.0023 & & & \\
\hline 4.69 & -3.04 & 4.95 & -16.64 & 3.24 & -4.02 & -1.59 & & & \\
\hline \multicolumn{10}{|c|}{ LTS (Least Trimmed Square)1\% } \\
\hline-0.0021 & 0.0011 & 0.0048 & -0.0637 & 0.0098 & -0.0007 & -0.0104 & & & \\
\hline-0.36 & 2.80 & 8.00 & -16.74 & 6.06 & -1.14 & -7.95 & & & \\
\hline $\begin{array}{l}\text { Panel B: } \\
\text { intercept } \\
O L S\end{array}$ & Ln(size) & $\ln (\mathbf{b} / \mathbf{m})$ & $\operatorname{ret}(-1:-1)$ & $\operatorname{ret}(-12:-1)$ & ret(-36:-13) & Accruals & NOA & CFO & LOSS \\
\hline 0.0329 & -0.0014 & 0.0031 & -0.0712 & 0.0045 & -0.0021 & -0.0044 & -0.0050 & 0.0063 & -0.0018 \\
\hline 5.25 & -3.29 & 4.64 & -17.10 & 2.83 & -3.72 & -1.81 & -7.25 & 3.22 & -1.34 \\
\hline \multicolumn{10}{|l|}{ LTS $1 \%$} \\
\hline 0.0009 & 0.0010 & 0.0049 & -0.0652 & 0.0088 & -0.0006 & 0.0032 & -0.0049 & 0.0129 & -0.0079 \\
\hline 0.16 & 2.56 & 7.98 & -17.21 & 5.59 & -1.08 & 1.37 & -7.86 & 7.12 & -6.48 \\
\hline
\end{tabular}

Note:

Variable Measurement

Raw NOA = Operating Assets (OA)-Operating Liabilities (OL), where

(Compustat item numbers in parentheses)

$\mathrm{OA}=$ Total Assets (\#6) - Cash and short term investment (\#1)

$\mathrm{OL}=$ Total Assets - STD - LTD - MI - PS - CE

STD = Debts included in current liabilities (\#34)

LTD = Long term debts (\#9)

MI = Minority interests (\#38)

PS = Preferred stocks (\#130)

$\mathrm{CE}=$ Common equity (\#60)

NOA $=$ Raw NOA /Lagged total assets

Raw Accruals $=(\Delta \mathrm{CA}-\Delta \mathrm{Cash})-(\Delta \mathrm{CL}-\Delta \mathrm{STD}-\Delta \mathrm{TP})-\mathrm{Dep}$, where $\Delta$ is the annual change,

$\mathrm{CA}=$ Current assets $(\# 4)$

$\mathrm{CL}=$ Current liabilities (\#5)

$\mathrm{TP}=$ Income tax payable $(\# 71)$

Dep = Depreciation and amortization (\#14)

Accruals = Raw accruals / Lagged total assets

Earnings = Income from continuing operations (\#178)/lagged total assets

CFO = Earnings-Accruals

LOSS $\quad=1$ if Earnings $<0$; otherwise 0 .

Every month $t$ between July, 1964 and December, 2002, the cross-section of stock returns are regressed on $\ln ($ size) where size is defined as the log of the firm's market capitalization; $\ln (\mathrm{B} / \mathrm{M})$ which is the log of the book-to-market ratio; the previous month's return on the stock, denoted ret(-1: -1$)$; the previous year's return on the stock from month $t-12$ to $t-2$, denoted ret $(-12$ : -2$)$; the return on the stock starting from month $t-36$ to $t-13$, denoted ret(-36: -13$)$, Accruals, CFO, NOA and LOSS dummy with or without truncation. There is a minimum of a four-month gap between the fiscal year end and the return month in month $t$ regressions. The time-series average of the monthly coefficient estimates and their associated time-series $t$-statistics (in italics) are reported. Bold numbers indicate significance at less than $5 \%$ level (2-tailed $t$-test). 


\begin{tabular}{c|ccc}
\hline \multicolumn{4}{c}{ TABLE } \\
\multicolumn{5}{c}{$\mathbf{3}$} \\
Frequency of Loss Firms Across Accruals/CFO/NOA Deciles \\
\hline $\begin{array}{c}\text { decile } \\
\text { ranking }\end{array}$ & Accrual & CFO & NOA \\
\hline 1 & $42.2 \%$ & $58.6 \%$ & $39.6 \%$ \\
2 & $25.1 \%$ & $43.1 \%$ & $28.5 \%$ \\
3 & $17.7 \%$ & $29.4 \%$ & $20.6 \%$ \\
4 & $13.9 \%$ & $17.0 \%$ & $16.2 \%$ \\
5 & $12.4 \%$ & $9.3 \%$ & $13.2 \%$ \\
6 & $12.3 \%$ & $5.4 \%$ & $11.0 \%$ \\
7 & $13.0 \%$ & $3.8 \%$ & $9.9 \%$ \\
8 & $12.4 \%$ & $3.2 \%$ & $9.7 \%$ \\
9 & $12.3 \%$ & $2.7 \%$ & $10.4 \%$ \\
10 & $14.0 \%$ & $2.9 \%$ & $16.3 \%$ \\
\hline
\end{tabular}

Note:

This table reports the frequency of Loss firms across Accruals, CFO and NOA deciles. Every month, the number of loss firms to total firms is counted for every decile. Then the time-series average of the percentage of loss firms is reported. 


\section{TABLE 4}

Pooled Monthly Returns Regressed on Size and Decile Ranks Dummy by Accruals, Cash Flow from Operation and NOA for Ordinary Least Square (OLS) vs. Least Trimmed Squares (LTS)

\begin{tabular}{|c|c|c|c|c|c|c|c|c|c|}
\hline \multicolumn{10}{|c|}{ Panel A: Accruals } \\
\hline Intercept & $\ln ($ size) & DL_acc & D2_acc & D3_acc & D4_acc & D7_acc & D8_acc & D9_acc & DH_acc \\
\hline \multicolumn{10}{|c|}{ Pooled OLS (Ordinary Least Squares) } \\
\hline 0.0413 & -0.0024 & -0.0034 & -0.0007 & 0.0017 & 0.0006 & -0.001 & -0.0029 & -0.0052 & -0.0123 \\
\hline 45.34 & -33.33 & -5.78 & -1.14 & 2.92 & 1.02 & -1.77 & -4.95 & -8.84 & -20.81 \\
\hline \multicolumn{10}{|c|}{ Pooled LTS (Least Trimmed Squares) 1\% } \\
\hline 0.0064 & 0.0001 & -0.0115 & -0.0027 & 0.0006 & 0.0004 & -0.0012 & -0.0023 & -0.0056 & -0.0138 \\
\hline 8.81 & 1.46 & -24.37 & -5.80 & 1.33 & 0.85 & -2.52 & -4.84 & -11.92 & -29.40 \\
\hline \multicolumn{10}{|c|}{ Panel B: Cash Flow from Operation } \\
\hline Intercept & $\ln ($ size $)$ & DL_cfo & D2_cfo & D3_cfo & D4_cfo & D7_cfo & D8_cfo & D9_cfo & DH_cfo \\
\hline \multicolumn{10}{|l|}{ Pooled OLS } \\
\hline 0.0455 & -0.0028 & -0.0110 & -0.0062 & -0.0038 & -0.0023 & 0.0015 & 0.0031 & 0.0027 & 0.0020 \\
\hline 48.33 & -37.14 & -17.99 & -10.47 & -6.45 & -3.99 & 2.63 & 5.24 & 4.61 & 3.46 \\
\hline \multicolumn{10}{|c|}{ Pooled LTS(1\%) } \\
\hline 0.0171 & -0.0008 & -0.0265 & -0.0156 & -0.0084 & -0.0042 & 0.0022 & 0.0039 & 0.0032 & 0.0021 \\
\hline 23.38 & -13.65 & -56.13 & -32.91 & -17.86 & -8.97 & 4.68 & 8.28 & 6.89 & 4.51 \\
\hline \multicolumn{10}{|c|}{ Panel C: NOA } \\
\hline Intercept & $\ln ($ size $)$ & DL_noa & D2_noa & D3_noa & D4_noa & D7_noa & D8_noa & D9_noa & DH_noa \\
\hline \multicolumn{10}{|l|}{ Pooled OLS } \\
\hline 0.0376 & -0.0021 & 0.0028 & 0.0019 & 0.0007 & 0.0009 & -0.0014 & -0.0044 & -0.0064 & -0.0152 \\
\hline 42.62 & -29.36 & 4.70 & 3.19 & 1.28 & 1.61 & -2.31 & -7.54 & -10.98 & -25.94 \\
\hline \multicolumn{10}{|c|}{ Pooled LTS (1\%) } \\
\hline 0.0030 & 0.0004 & -0.0055 & -0.0037 & -0.0015 & -0.0005 & -0.0008 & -0.0037 & -0.0064 & -0.0170 \\
\hline 4.28 & 7.29 & -11.67 & -7.92 & -3.25 & -1.10 & -1.72 & -7.92 & -13.79 & -36.41 \\
\hline
\end{tabular}

Note: The return measurement period begins four months after the firm's fiscal year end. The indicator variable DL_Acc (CFO, NOA) is set to 1 if the firm is in the lowest Accruals (CFO, NOA) decile in a particular calendar month 0 otherwise. The indicator variable DH_Acc (CFO, NOA) is set to 1 if the firm is in the highest Accruals (CFO, NOA) decile in a particular calendar month 0 otherwise. D2_Acc (CFO, NOA) to D9_Acc(CFO, NOA) are indicator variables set to one if the firm is in the corresponding Accruals (CFO, NOA) decile. 


\begin{tabular}{|c|c|c|c|c|c|c|c|c|c|}
\hline \multicolumn{10}{|c|}{ 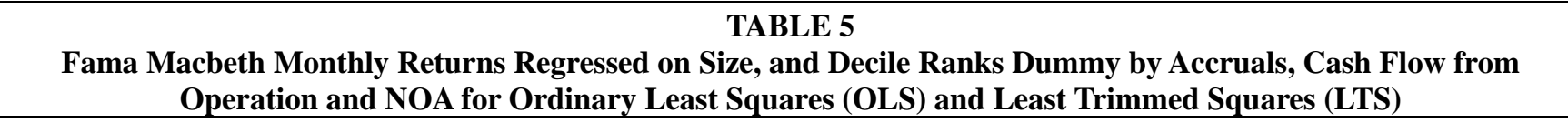 } \\
\hline \multicolumn{10}{|c|}{ Panel A: Accruals } \\
\hline Intercept & $\ln (\operatorname{size})$ & DL_acc & D2_acc & D3_acc & D4_acc & D7_acc & D8_acc & D9_acc & DH_acc \\
\hline \multicolumn{10}{|c|}{ OLS (Ordinary Least Squares) } \\
\hline 0.0347 & -0.0019 & -0.0015 & -0.0001 & 0.0017 & 0.0009 & -0.0007 & -0.0022 & -0.0045 & -0.0107 \\
\hline 5.08 & -4.00 & -0.87 & -0.08 & 2.99 & 1.79 & -1.26 & -3.27 & -5.00 & -7.52 \\
\hline \multicolumn{10}{|c|}{ LTS (Least Trimmed Square)1\% } \\
\hline-0.0038 & 0.001 & -0.0061 & -0.0006 & 0.0013 & 0.0010 & -0.0003 & -0.0008 & -0.0036 & -0.0104 \\
\hline-0.61 & 2.34 & -3.87 & -0.83 & 2.54 & 2.25 & -0.61 & -1.29 & -4.24 & -7.64 \\
\hline \multicolumn{10}{|c|}{ Panel B: Cash Flow from Operation } \\
\hline Intercept & $\ln ($ size $)$ & DL_cfo & D2_cfo & D3_cfo & D4_cfo & D7_cfo & D8_cfo & D9_cfo & DH_cfo \\
\hline \multicolumn{10}{|l|}{ OLS } \\
\hline 0.0385 & -0.0022 & -0.0093 & -0.0052 & -0.0029 & -0.0019 & 0.0011 & 0.0023 & 0.0020 & 0.0014 \\
\hline 6.03 & -5.01 & -3.75 & -3.04 & -2.59 & -3.10 & 2.30 & 4.52 & 3.51 & 1.57 \\
\hline \multicolumn{10}{|l|}{ LTS $1 \%$} \\
\hline 0.0044 & 0.0004 & -0.0188 & -0.0100 & -0.0047 & -0.0026 & 0.0011 & 0.0023 & 0.0020 & 0.0013 \\
\hline 0.74 & 0.93 & -8.42 & -6.49 & -4.58 & -4.75 & 2.62 & 4.84 & 3.61 & 1.51 \\
\hline \multicolumn{10}{|c|}{ Panel C: NOA } \\
\hline \multicolumn{9}{|l|}{ OLS } & DH_noa \\
\hline 0.0317 & -0.0016 & 0.0028 & 0.0018 & 0.0009 & 0.0007 & -0.0011 & -0.0039 & -0.005 & -0.0129 \\
\hline 4.55 & -3.42 & 1.65 & 1.43 & 1.16 & 1.27 & -2.34 & -7.70 & -7.38 & -9.16 \\
\hline \multicolumn{10}{|l|}{ LTS $1 \%$} \\
\hline-0.0059 & 0.0013 & -0.0016 & -0.0008 & -0.0004 & 0.0000 & -0.0010 & -0.0033 & -0.005 & -0.0136 \\
\hline-0.92 & 2.88 & -1.06 & -0.69 & -0.61 & 0.08 & -2.35 & -7.27 & -8.06 & -10.01 \\
\hline
\end{tabular}

Note: All variables are defined in Table 1. Every month $t$ between July, 1964 and December, 2002, the cross-section of stock returns are regressed on $\ln ($ size) where size is defined as the log of the firm's market capitalization and Decile Rank Indicators for variable of interested with (LTS) or without truncation (OLS). There is a minimum of a four-month gap between the fiscal year end and the return month in month $t$ regressions. The time-series average of the monthly coefficient estimates and their associated time-series $t$-statistics (in italics) are reported. Bold numbers indicate significance at less than $5 \%$ level (2-tailed $t$-test). 
TABLE 6

Fama Macbeth Monthly Regressions of Returns on Size, B/M, One Month Reversal, Twelve Month Momentum, Thirty Six Month Reversal and Decile Rankings Dummy by Accruals, Cash Flow from Operations and NOA for Ordinary Least Square vs. Trimmed Least Square

\begin{tabular}{|c|c|c|c|c|c|c|c|c|c|c|c|c|c|}
\hline \multicolumn{14}{|c|}{ Panel A: Accruals } \\
\hline intercept & $\ln ($ size $)$ & $\ln (\mathbf{b} / \mathbf{m})$ & $\operatorname{Ret}(-1:-1)$ & $\operatorname{Ret}(-12:-1)$ & $\operatorname{Ret}(-36:-13)$ & DL_acc & D2_acc & D3_acc & D4_acc & D7_acc & D8_acc & D9_acc & DH_acc \\
\hline \multicolumn{14}{|c|}{ OLS (Ordinary Least Square) } \\
\hline 0.0296 & -0.0014 & 0.0029 & -0.0697 & 0.0055 & -0.0018 & 0.0001 & 0.0004 & 0.0020 & 0.0008 & -0.0005 & -0.0013 & -0.0031 & -0.0082 \\
\hline 4.46 & -2.89 & 4.18 & -16.35 & 3.33 & -2.95 & 0.09 & 0.53 & 3.70 & 1.78 & -0.93 & -2.14 & -4.40 & -8.17 \\
\hline \multicolumn{14}{|c|}{ LTS (Least Trimmed Square)1\% } \\
\hline-0.0082 & 0.0015 & 0.0050 & -0.0632 & 0.0104 & 0.0002 & -0.0031 & 0.0003 & 0.0016 & 0.0011 & 0.0001 & 0.0003 & -0.0017 & -0.0070 \\
\hline-1.36 & 3.58 & 7.99 & -16.28 & 6.40 & 0.41 & -3.06 & 0.54 & 3.39 & 2.59 & 0.16 & 0.47 & -2.58 & -7.27 \\
\hline \multicolumn{14}{|c|}{ Panel B: Cash Flow from Operation } \\
\hline $\begin{array}{l}\text { intercept } \\
O L S\end{array}$ & $\ln ($ size $)$ & $\ln (\mathbf{b} / \mathbf{m})$ & $\operatorname{Ret}(-1:-1)$ & $\operatorname{Ret}(-12:-1)$ & $\operatorname{Ret}(-36:-13)$ & DL_cfo & D2_cfo & D3_cfo & D4_cfo & D7_cfo & D8_cfo & D9_cfo & DH_cfo \\
\hline 0.0315 & -0.0016 & 0.0036 & -0.0707 & 0.0049 & -0.0026 & -0.0053 & -0.0039 & -0.0026 & -0.0020 & 0.0017 & 0.0032 & 0.0038 & 0.0055 \\
\hline 5.11 & -3.67 & 5.46 & -16.84 & 3.04 & -4.29 & -3.30 & -3.16 & -3.04 & -3.40 & 3.71 & 6.78 & 6.82 & 8.21 \\
\hline \multicolumn{14}{|l|}{$\operatorname{LTS} 1 \%$} \\
\hline-0.0018 & 0.001 & 0.0051 & -0.0650 & 0.0095 & -0.0006 & -0.0129 & -0.0075 & -0.0038 & -0.0023 & 0.0016 & 0.003 & 0.0035 & 0.0052 \\
\hline-0.32 & 2.54 & 8.39 & -16.86 & 5.94 & -1.03 & -8.99 & -7.10 & -4.85 & -4.72 & 3.87 & 6.83 & 7.05 & 8.41 \\
\hline \multicolumn{14}{|c|}{ Panel C: NOA } \\
\hline $\begin{array}{l}\text { intercept } \\
O L S\end{array}$ & $\ln ($ size $)$ & $\ln (\mathbf{b} / \mathbf{m})$ & $\operatorname{Ret}(-1:-1)$ & $\operatorname{Ret}(-12:-1)$ & $\operatorname{Ret}(-36:-13)$ & DL_noa & D2_noa & D3_noa & D4_noa & D7_noa & D8_noa & D9_noa & DH_noa \\
\hline 0.0261 & -0.0010 & 0.0036 & -0.0701 & 0.0053 & -0.0017 & 0.0055 & 0.0029 & 0.0015 & 0.0011 & -0.0009 & -0.0035 & -0.0038 & -0.0106 \\
\hline 3.89 & -2.19 & 5.44 & -16.48 & 3.19 & -2.85 & 4.62 & 3.24 & 2.40 & 2.03 & -1.80 & -7.03 & -6.28 & -11.12 \\
\hline \multicolumn{14}{|l|}{ LTS $1 \%$} \\
\hline-0.0106 & 0.0018 & 0.0056 & -0.0634 & 0.0103 & 0.0003 & 0.0024 & 0.0011 & 0.0007 & 0.0005 & -0.0006 & -0.0027 & -0.0034 & -0.0102 \\
\hline-1.73 & 4.23 & 9.24 & -16.48 & 6.33 & 0.53 & 2.33 & 1.32 & 1.25 & 1.11 & -1.50 & -6.34 & -6.32 & -11.21 \\
\hline
\end{tabular}

Note:

Every month $t$ between July, 1964 and December, 2002, the cross-section of stock returns are regressed on ln(size) where size is defined as the log of the firm's market capitalization; $\ln (\mathrm{B} / \mathrm{M})$ which is the log of the book-to-market ratio; the previous month's return on the stock, denoted ret(-1: -1$)$; the previous year's return on the stock from month $t-12$ to $t-2$, denoted ret $(-12:-2)$; the return on the stock starting from month $t-36$ to $t-13$, denoted ret(-36: -13) and decile ranking dummy of financial variable interested with (LTS) or without truncation (OLS). There is a minimum of a four-month gap between the fiscal year end and the return month in month $t$ regressions. The time-series average of the monthly coefficient estimates and their associated time-series $t$-statistics (in italics) are reported. Bold numbers indicate significance at less than $5 \%$ level (2-tailed $t$-test). 


\begin{tabular}{|c|c|c|c|}
\hline \multicolumn{4}{|c|}{$\begin{array}{c}\text { TABLE } 7 \\
\text { Mean Skewness across Accruals/CFO/NOA Deciles }\end{array}$} \\
\hline \multicolumn{4}{|l|}{ Panel A: All-firm Sample } \\
\hline decile ranking & Accrual & CFO & NOA \\
\hline 1 & 2.1763 & 2.004 & 2.1173 \\
\hline 2 & 1.7484 & 1.9669 & 1.9548 \\
\hline 3 & 1.9006 & 2.0559 & 1.9204 \\
\hline 4 & 1.6696 & 1.6792 & 1.6549 \\
\hline 5 & 1.7138 & 1.7404 & 1.7959 \\
\hline 6 & 1.7068 & 1.4887 & 1.6362 \\
\hline 7 & 1.7476 & 1.4895 & 1.7061 \\
\hline 8 & 1.5249 & 1.3511 & 1.5112 \\
\hline 9 & 1.6302 & 1.3058 & 1.5104 \\
\hline 10 & 1.4264 & 1.1166 & 1.2786 \\
\hline Difference in Skewness (1-10) & 0.75 & 0.88 & 0.84 \\
\hline t-statistics & 6.24 & 7.99 & 7.23 \\
\hline \multicolumn{4}{|l|}{ Panel B: Profit-firm sample } \\
\hline decile ranking & Accrual & CFO & NOA \\
\hline 1 & 1.3182 & 1.2934 & 1.4168 \\
\hline 2 & 1.3595 & 1.5203 & 1.3279 \\
\hline 3 & 1.3781 & 1.3726 & 1.3973 \\
\hline 4 & 1.3478 & 1.5402 & 1.3121 \\
\hline 5 & 1.354 & 1.308 & 1.3266 \\
\hline 6 & 1.2244 & 1.2422 & 1.3483 \\
\hline 7 & 1.2756 & 1.2087 & 1.252 \\
\hline 8 & 1.2276 & 1.0878 & 1.1431 \\
\hline 9 & 1.2279 & 1.0055 & 1.198 \\
\hline 10 & 1.0485 & 0.8729 & 1.0037 \\
\hline Difference in Skewness (1-10) & 0.26 & 0.42 & 0.41 \\
\hline t-statistics & 3.46 & 5.80 & 4.60 \\
\hline
\end{tabular}

Note: All variables are defined in table I. Eevery month between July, 1964 and December, 2002, firms are assigned into decile portfolios based on Accruals, CFO or NOA of the nearest available fiscal year. To allow for a minimum of a four-month lag between the fiscal year end and the return month, all returns are measured from the $5^{\text {th }}$ month to the $16^{\text {th }}$ month after the fiscal year end. The hedge portfolio consists of a long position in the highest ranked portfolio and an offsetting short position in the lowest ranked portfolio. The time-series return skewness for each decile are reported. 
TABLE 8

Truncation Bias in Full Sample and Profit Sample

\begin{tabular}{|c|c|c|c|c|c|c|c|c|c|c|}
\hline & \multicolumn{5}{|c|}{ All-firm Sample } & \multicolumn{5}{|c|}{ Profit-firm Sample } \\
\hline & \multicolumn{2}{|c|}{\begin{tabular}{cc}
\multicolumn{2}{c}{ Abnormal ret $>=0$} \\
& total \\
& return \\
\# of obs & $\%$ \\
deleted & deleted \\
\end{tabular}} & \multicolumn{2}{|c|}{\begin{tabular}{cc}
\multicolumn{2}{c}{ Abnormal } \\
& Ret $<0$ \\
& rotal \\
& return \\
\# of obs & $\%$ \\
deleted & deleted \\
\end{tabular}} & $\begin{array}{c}\text { Total } \\
\text { Return } \\
\% \\
\text { deleted } \\
\end{array}$ & $\begin{array}{c}\text { \# of } \\
\text { obs } \\
\text { deleted } \\
\end{array}$ & $\begin{array}{l}\text { al ret }>=0 \\
\text { total } \\
\text { return } \\
\% \\
\text { deleted } \\
\end{array}$ & $\begin{array}{c}\text { \# of } \\
\text { obs } \\
\text { deleted } \\
\end{array}$ & $\begin{array}{c}\text { al Ret }<0 \\
\text { total } \\
\text { return } \\
\% \\
\text { deleted } \\
\end{array}$ & $\begin{array}{c}\text { Total } \\
\text { return } \\
\% \\
\text { deleted } \\
\end{array}$ \\
\hline \multicolumn{11}{|c|}{ Panel A: Accrual } \\
\hline 1 & 2890 & 292,598 & 499 & $-31,941$ & 260,657 & 1431 & 96,128 & 283 & $-14,152$ & 81,976 \\
\hline 2 & 1713 & 161,118 & 215 & $-13,794$ & 147,324 & 926 & 64,462 & 191 & $-9,609$ & 54,853 \\
\hline 3 & 1262 & 125,573 & 153 & $-9,699$ & 115,874 & 860 & 58,192 & 126 & $-5,882$ & 52,310 \\
\hline 4 & 1047 & 96,077 & 101 & $-6,509$ & 89,568 & 725 & 48,233 & 128 & $-6,308$ & 41,925 \\
\hline 5 & 944 & 87,094 & 109 & $-6,940$ & 80,154 & 759 & 49,832 & 146 & $-7,089$ & 42,743 \\
\hline 6 & 995 & 90,153 & 92 & $-5,906$ & 84,247 & 770 & 49,528 & 147 & $-7,210$ & 42,318 \\
\hline 7 & 1104 & 102,492 & 131 & $-8,545$ & 93,947 & 917 & 60,691 & 174 & $-8,749$ & 51,942 \\
\hline 8 & 1099 & 99,267 & 126 & $-8,163$ & 91,104 & 1039 & 69,555 & 223 & $-10,873$ & 58,682 \\
\hline 1 & 1362 & 124,961 & 129 & $-8,074$ & 116,887 & 1248 & 83,979 & 274 & $-13,351$ & 70,628 \\
\hline 10 & 1738 & 153,792 & 265 & $-17,472$ & 136,320 & 1689 & 109,573 & 472 & $-23,701$ & 85,872 \\
\hline$(1-10)$ & 1152 & 138,806 & 234 & $-14,469$ & 124,337 & -258 & $-13,444$ & -189 & 9,548 & $-3,896$ \\
\hline \multicolumn{11}{|c|}{ Panel B: CFO } \\
\hline 1 & 3841 & 374,879 & 557 & $-36,310$ & 338,569 & 1988 & 135,285 & 471 & $-24,095$ & 111,190 \\
\hline 2 & 2787 & 272,123 & 338 & $-22,074$ & 250,049 & 1429 & 100,556 & 297 & $-14,834$ & 85,722 \\
\hline 3 & 1893 & 183,016 & 232 & $-14,786$ & 168,230 & 1111 & 73,077 & 229 & $-11,127$ & 61,950 \\
\hline 4 & 1359 & 125,596 & 149 & $-9,554$ & 116,042 & 925 & 64,492 & 204 & $-10,534$ & 53,958 \\
\hline 5 & 935 & 86,835 & 116 & $-7,478$ & 79,357 & 869 & 57,631 & 144 & $-6,756$ & 50,875 \\
\hline 6 & 750 & 67,918 & 94 & $-6,158$ & 61,760 & 774 & 51,138 & 132 & $-6,746$ & 44,392 \\
\hline 7 & 678 & 59,198 & 73 & $-4,583$ & 54,615 & 762 & 49,994 & 125 & $-6,376$ & 43,618 \\
\hline 8 & 593 & 51,066 & 61 & $-3,934$ & 47,132 & 728 & 46,755 & 134 & $-6,229$ & 40,526 \\
\hline 1 & 601 & 52,387 & 60 & $-3,799$ & 48,588 & 763 & 48,086 & 148 & $-7,159$ & 40,927 \\
\hline 10 & 747 & 62,067 & 110 & $-6,722$ & 55,345 & 1019 & 63,397 & 276 & $-12,895$ & 50,502 \\
\hline$(1-10)$ & 3094 & 312,812 & 447 & $-29,588$ & 283,224 & 969 & 71,888 & 195 & $-11,200$ & 60,688 \\
\hline \multicolumn{11}{|c|}{ Panel C: NOA } \\
\hline 1 & 2756 & 275,237 & 343 & -22289 & 252,948 & 1414 & 96,572 & 277 & $-13,191$ & 83,381 \\
\hline 2 & 2138 & 206,631 & 256 & -16233 & 190,398 & 1123 & 74,165 & 206 & $-10,095$ & 64,070 \\
\hline 3 & 1549 & 146,018 & 201 & -12886 & 133,132 & 1069 & 71,500 & 158 & $-7,561$ & 63,939 \\
\hline 4 & 1243 & 113,616 & 100 & -6561 & 107,055 & 908 & 61,373 & 168 & $-8,156$ & 53,217 \\
\hline 5 & 1065 & 104,328 & 135 & -8639 & 95,689 & 892 & 58,934 & 149 & $-7,286$ & 51,648 \\
\hline 6 & 953 & 85,944 & 109 & -6974 & 78,970 & 879 & 60,300 & 164 & $-7,650$ & 52,650 \\
\hline 7 & 895 & 84,866 & 98 & -6134 & 78,732 & 874 & 58,659 & 161 & $-8,186$ & 50,473 \\
\hline 8 & 925 & 84,696 & 114 & -7325 & 77,371 & 882 & 58,216 & 200 & $-9,915$ & 48,301 \\
\hline 1 & 1102 & 98,478 & 158 & -10400 & 88,078 & 1022 & 66,176 & 224 & $-11,363$ & 54,813 \\
\hline 10 & 1533 & 133,286 & 301 & -19211 & 114,075 & 1294 & 83,935 & 464 & $-23,704$ & 60,231 \\
\hline$(1-10)$ & 1223 & 141,951 & 42 & -3078 & 138,873 & 120 & 12,637 & -187 & 10,513 & 23,150 \\
\hline
\end{tabular}

Note: All variables are as defined in Table 1. Every month between July 1964 to December 2002, firms are assigned into decile portfolios based on Accruals, CFO or NOA available from the nearest fiscal year, assuming a minimum 4-month gap between fiscal year end and the availability of annual accounting data. The hedge portfolio consists of a long position in the highest ranked portfolio and an offsetting short position in the lowest ranked portfolio. The total number of observations deleted and the sum of abnormal returns deleted are reported for positive abnormal return and negative abnormal return observations respectively for each decile. 


\section{TABLE 9}

Profit Firms Sample: Fama-Macbeth Monthly Regressions of Returns on Size, B/M, One Month Reversal, Twelve Month Momentum, Thirty Six Month Reversal and Decile Rankings Dummies by Accruals, Cash Flow from Operations and NOA for Ordinary Least Squares (OLS) and Least Trimmed Squares (LTS)

\begin{tabular}{|c|c|c|c|c|c|c|c|c|c|c|c|c|c|}
\hline \multicolumn{14}{|c|}{ Panel A: Accruals } \\
\hline \multicolumn{14}{|c|}{ OLS (Ordinary Least Square) } \\
\hline 0.0272 & -0.0012 & 0.0021 & -0.0615 & 0.0073 & -0.0014 & 0.0022 & 0.0018 & 0.0019 & 0.0015 & -0.0002 & -0.001 & -0.003 & -0.0081 \\
\hline 4.61 & -2.97 & 3.27 & -15.18 & 4.56 & -2.62 & 3.19 & 3.28 & 3.81 & 3.44 & -0.48 & -1.70 & -4.11 & -7.60 \\
\hline \multicolumn{14}{|c|}{ LTS (Least Trimmed Square)1\% } \\
\hline-0.0013 & 0.0009 & 0.0031 & -0.0603 & 0.0101 & -0.0003 & 0.0012 & 0.0015 & 0.0014 & 0.0013 & 0.0001 & -0.0008 & -0.0025 & -0.0082 \\
\hline-0.24 & 2.41 & 5.16 & -15.77 & 6.39 & -0.47 & 2.01 & 3.01 & 3.19 & 3.26 & 0.28 & -1.39 & -3.71 & -8.24 \\
\hline \multicolumn{14}{|c|}{ Panel B: Cash Flow from Operation } \\
\hline \multicolumn{14}{|l|}{ OLS } \\
\hline 0.0278 & -0.0012 & 0.0036 & -0.0617 & 0.0069 & -0.002 & -0.0079 & -0.0031 & -0.0025 & -0.0012 & 0.0016 & 0.0021 & 0.0029 & 0.0040 \\
\hline 4.69 & -2.92 & 5.04 & -15.23 & 4.37 & -3.62 & -8.85 & -4.64 & -4.86 & -2.47 & 3.64 & 4.91 & 5.32 & 5.90 \\
\hline \multicolumn{14}{|l|}{ LTS $1 \%$} \\
\hline 0.0001 & 0.0009 & 0.0047 & -0.0605 & 0.0096 & -0.0008 & -0.0096 & -0.0041 & -0.0029 & -0.0014 & 0.0015 & 0.002 & 0.0032 & 0.0039 \\
\hline 0.02 & 2.36 & 7.09 & -15.77 & 6.08 & -1.49 & -11.87 & -6.72 & -6.16 & -3.22 & 3.68 & 5.24 & 6.40 & 6.38 \\
\hline \multicolumn{14}{|c|}{ Panel C: NOA } \\
\hline $\begin{array}{l}\text { intercept } \\
O L S\end{array}$ & $\ln ($ size $)$ & $\ln (\mathbf{b} / \mathbf{m})$ & $\operatorname{Ret}(-1:-1)$ & $\operatorname{Ret}(-12:-1)$ & $\operatorname{Ret}(-36:-13)$ & DL_noa & D2_noa & D3_noa & D4_noa & D7_noa & D8_noa & D9_noa & DH_noa \\
\hline 0.0026 & -0.0010 & 0.0026 & -0.0062 & 0.0070 & -0.0015 & 0.0040 & 0.0019 & 0.0018 & 0.0008 & -0.0012 & -0.0032 & -0.0037 & -0.0089 \\
\hline 4.15 & -2.41 & 4.00 & -15.16 & 4.38 & -2.76 & 5.40 & 3.27 & 3.72 & 1.94 & -2.54 & -6.85 & -6.19 & -10.93 \\
\hline \multicolumn{14}{|l|}{ LTS $1 \%$} \\
\hline-0.0029 & 0.0011 & 0.0035 & -0.0601 & 0.0098 & -0.0003 & 0.0032 & 0.0013 & 0.0008 & 0.0006 & -0.0009 & -0.0026 & -0.0034 & -0.0087 \\
\hline-0.51 & 2.87 & 5.84 & -15.69 & 6.20 & -0.53 & 4.82 & 2.47 & 1.98 & 1.57 & -2.13 & -5.99 & -6.36 & -11.13 \\
\hline $\begin{array}{l}\text { previous } \\
\text { return on } \\
\text { without } t\end{array}$ & is samp & ing fror & month $t-$ & et $(-1:-1)$ & $\begin{array}{l}\text { previous y } \\
\text { between ret }-36 \\
\text { ated time-se }\end{array}$ & 13), & d decile & $\begin{array}{l}\text { k from } \\
\text { king d } \\
\text { le retur } \\
\text { Cs) are }\end{array}$ & $\begin{array}{l}\text { onth } t- \\
\text { nmies fo } \\
\text { nonth in } \\
\text { ported. }\end{array}$ & $\begin{array}{l}\text { e cross-se } \\
\text { og of the } \\
2 \text { to } t-2 \text {, } \\
\text { financial } \\
\text { nonth } t \text { re } \\
\text { ld numbe }\end{array}$ & $\begin{array}{l}\text { ection of } \\
\text { book-to- } \\
\text { denoted } \\
\text { variable } \\
\text { gressions } \\
\text { ers indica }\end{array}$ & $\begin{array}{l}\text { tock retu } \\
\text { narket ra } \\
\text { t }(-12:- \\
\text { terested } \\
\text { The time } \\
\text { sionific }\end{array}$ & $\begin{array}{l}\text { ns are } \\
\text { io; the } \\
\text { 2); the } \\
\text { vith or } \\
\text {-series } \\
\text { ince at }\end{array}$ \\
\hline
\end{tabular}




\begin{tabular}{|c|c|c|c|}
\hline \multicolumn{4}{|c|}{$\begin{array}{l}\text { TABLE } 10 \\
\text { Industry Distribution of Loss Firms with Extreme Large Monthly Returns (>100\%) }\end{array}$} \\
\hline & Industry & Average Extreme Ret & \#obs \\
\hline 1 & Agric & $179.4 \%$ & 12 \\
\hline 2 & Food & $159.7 \%$ & 20 \\
\hline 3 & Soda & $158.8 \%$ & 4 \\
\hline 4 & Beer & $125.0 \%$ & 2 \\
\hline 5 & Smoke & $183.3 \%$ & 1 \\
\hline 6 & Toys & $188.4 \%$ & 24 \\
\hline 7 & Fun & $156.7 \%$ & 55 \\
\hline 8 & Books & $150.6 \%$ & 22 \\
\hline 9 & Hshld & $144.5 \%$ & 39 \\
\hline 10 & Clths & $164.6 \%$ & 26 \\
\hline 11 & Hlth & $172.9 \%$ & 61 \\
\hline 12 & MedEq & $168.8 \%$ & 128 \\
\hline 13 & Drugs & $157.2 \%$ & 273 \\
\hline 14 & Chems & $162.3 \%$ & 12 \\
\hline 15 & Rubbr & $178.0 \%$ & 16 \\
\hline 16 & Txtls & $147.5 \%$ & 8 \\
\hline 17 & BldMt & $186.6 \%$ & 45 \\
\hline 18 & Cnstr & $171.5 \%$ & 19 \\
\hline 19 & Steel & $152.6 \%$ & 15 \\
\hline 20 & FabPr & $145.2 \%$ & 9 \\
\hline 21 & Mach & $179.1 \%$ & 64 \\
\hline 22 & ElcEq & $164.4 \%$ & 11 \\
\hline 23 & Misc & $195.3 \%$ & 76 \\
\hline 24 & Autos & $132.7 \%$ & 8 \\
\hline 25 & Aero & $157.2 \%$ & 8 \\
\hline 26 & Ships & $114.3 \%$ & 1 \\
\hline 27 & Guns & $158.8 \%$ & 2 \\
\hline 28 & Gold & $160.5 \%$ & 58 \\
\hline 29 & Mines & $152.4 \%$ & 18 \\
\hline 30 & Coal & $149.8 \%$ & 2 \\
\hline 31 & Enrgy & $169.9 \%$ & 157 \\
\hline 32 & Util & $173.9 \%$ & 38 \\
\hline 33 & Telcm & $178.1 \%$ & 127 \\
\hline 34 & PerSv & $210.2 \%$ & 19 \\
\hline 35 & BusSv & $172.9 \%$ & 680 \\
\hline 36 & Comps & $174.5 \%$ & 309 \\
\hline 37 & Chips & $162.8 \%$ & 217 \\
\hline 38 & LabEq & $159.0 \%$ & 61 \\
\hline 39 & Paper & $179.1 \%$ & 14 \\
\hline 40 & Boxes & $150.1 \%$ & 9 \\
\hline 41 & Trans & $175.1 \%$ & 27 \\
\hline 42 & Whlsl & $179.5 \%$ & 129 \\
\hline 43 & Rtail & $175.7 \%$ & 109 \\
\hline 44 & Meals & $167.1 \%$ & 43 \\
\hline 45 & Banks & $187.9 \%$ & 12 \\
\hline 46 & Insur & $152.4 \%$ & 16 \\
\hline 47 & RlEst & $176.8 \%$ & 18 \\
\hline 48 & Fin & $167.1 \%$ & 58 \\
\hline
\end{tabular}


